\title{
Evaluation of linear ozone photochemistry parametrizations in a stratosphere-troposphere data assimilation system
}

\author{
A. J. Geer ${ }^{1, *}$, W. A. Lahoz ${ }^{1}$, D. R. Jackson ${ }^{2}$, D. Cariolle ${ }^{3}$, and J. P. McCormack ${ }^{4}$ \\ ${ }^{1}$ Data Assimilation Research Centre (DARC), University of Reading, Reading, UK \\ ${ }^{2}$ Met Office, Exeter, UK \\ ${ }^{3}$ Centre Européen de Recherche et Formation Avancée en Calcul Scientifique (CERFACS), Toulouse, France and \\ Météo-France, Toulouse, France \\ ${ }^{4}$ E. O. Hulburt Center for Space Research, Naval Research Laboratory (NRL), Washington D.C., USA \\ *now at: European Centre for Medium-Range Weather Forecasts (ECMWF), Reading, UK
}

Received: 18 May 2006 - Published in Atmos. Chem. Phys. Discuss.: 4 August 2006

Revised: 28 November 2006 - Accepted: 14 February 2007 - Published: 21 February 2007

\begin{abstract}
This paper evaluates the performance of various linear ozone photochemistry parametrizations using the stratosphere-troposphere data assimilation system of the Met Office. A set of experiments were run for the period 23 September 2003 to 5 November 2003 using the Cariolle (v1.0 and v2.1), LINOZ and Chem2D-OPP (v0.1 and v2.1) parametrizations. All operational meteorological observations were assimilated, together with ozone retrievals from the Michelson Interferometer for Passive Atmospheric Sounding (MIPAS). Experiments were validated against independent data from the Halogen Occultation Experiment (HALOE) and ozonesondes. Additionally, a simple offline method for comparing the parametrizations is introduced.

It is shown that in the upper stratosphere and mesosphere, outside the polar night, ozone analyses are controlled by the photochemistry parametrizations and not by the assimilated observations. The most important factor in getting good results at these levels is to pay attention to the ozone and temperature climatologies in the parametrizations. There should be no discrepancies between the climatologies and the assimilated observations or the model, but there is also a competing demand that the climatologies be objectively accurate in themselves. Conversely, in the lower stratosphere outside regions of heterogeneous ozone depletion, the ozone analyses are dominated by observational increments and the photochemistry parametrizations have little influence.

We investigate a number of known problems in LINOZ and Cariolle v1.0 in more detail than previously, and we find discrepancies in Cariolle v2.1 and Chem2D-OPP v2.1, which are demonstrated to have been removed in the latest avail-
\end{abstract}

Correspondence to: A. J. Geer

(alan.geer@ecmwf.int) able versions (v2.8 and v2.6 respectively). In general, however, all the parametrizations work well through much of the stratosphere, helped by the presence of good quality assimilated MIPAS observations.

\section{Introduction}

Atmospheric ozone is of interest not just because of the problem of ozone depletion (e.g., WMO, 2003) but also for its basic role in controlling the temperature structure of the atmosphere through the absorption of solar and long-wave radiation. The distribution of atmospheric ozone results from the interaction of transport, chemistry, and radiation processes. A full description of the photochemistry of ozone would be extremely complicated, involving hundreds of chemical species and reactions, many of which are interlinked. A detailed approximation to this can be embodied in a chemistrytransport model (CTM) (e.g. Chipperfield, 1999; Rozanov et al., 1999; Errera and Fonteyn, 2001; Josse et al., 2004), which is driven by off-line meteorological analyses. However, in applications such as climate modelling and numerical weather prediction (NWP) or data assimilation (DA), it is often desirable to use a faster, simpler representation of ozone photochemistry.

Cariolle and Déqué (1986) developed a parametrization of ozone photochemistry based on a linearisation of the ozone tendency around an equilibrium state, using parameters derived from a CTM with more detailed chemistry. The parametrization depends only on temperature and ozone amount; hence no other chemically active species need be modelled. As well as saving computer resources, this

Published by Copernicus GmbH on behalf of the European Geosciences Union. 
prevents a mis-specified or poorly-known chemical species from causing a bias in the modelled ozone amount. Along with the original scheme of Cariolle and Déqué (1986, v1.0), an updated version has recently become available (Cariolle and Teyssèdre, 2007, v2), and coefficients have been independently developed by McLinden et al. (2000, the LINOZ scheme), McCormack et al. (2004, Chem2D-OPP v0.1) and McCormack et al. (2006, Chem2D-OPP v2). Table 1 summarises these developments. Linearised ozone photochemistry schemes are routinely used in data assimilation (e.g., Riishøjgaard, 2000; Eskes et al., 2003; Dethof and Hólm, 2004; Geer et al., 2006a,b) and in multi-year climate simulations (e.g., Hadjinicolaou et al., 1997). Recently, Taylor and Bourqui (2005) developed a fast ozone photochemistry scheme of intermediate complexity, and this may be very useful in the future. Historically, one of the simplest approaches has been to make ozone loss rates proportional to the ozone amount and to keep production rates fixed. This was tried in the GEOS ozone data assimilation system, but major limitations were found (Riishøjgaard, 2000; McCormack et al., 2006). This paper examines only the much-used linear approach of Cariolle and Déqué (1986).

A number of studies have indicated problems in the earlier generation of linear photochemistry schemes and the ozone distributions that they produce. LINOZ is unsuitable for use in the upper stratosphere (McCormack et al., 2004; Geer et al., 2006a). Version 1.0 of Cariolle and Déqué (1986) has a strong sensitivity to the overlying ozone amount (Geer et al., 2006b). Even small ozone differences can be important in general circulation models (GCMs): $\sim 10 \%$ variations in ozone amounts can result in changes in modelled temperatures of several Kelvin (Cariolle and Morcrette, 2006). Now that updated photochemistry schemes are available, it is useful to evaluate and understand their differences. The data assimilation (DA) framework presents an opportunity to do this.

We examine the performance of a number of different ozone photochemistry schemes in the stratospheretroposphere DA system of the Met Office. 3-D-Variational data assimilation (3D-Var) is used to assimilate all operational dynamical observations, plus ozone retrievals from the Michelson Interferometer for Passive Atmospheric Sounding (MIPAS) on the Envisat satellite. The analyses are validated against independent ozone data from sondes and the Halogen Occultation Experiment (HALOE).

Using a data assimilation system to evaluate a number of different parametrizations is a relatively novel approach. It is more typical to do such evaluations with multi-year free model runs. However, free- running models can evolve to a state that may be different from the real atmosphere; the regular insertion of observational data in a DA system acts to prevent this. With DA, model forecasts or analyses can be compared directly to observations in their synoptic context. However, there are limitations. A normally useful property of DA is that slow-growing model errors are swiftly cor- rected, but here, this means that such errors cannot easily be detected. Also, the NWP system used here is computationally expensive and experiments could be run only for short periods. A better choice in future for such experiments would be a CTM-based data assimilation system, computationally much cheaper. This paper does not eliminate the need to examine linear ozone parametrizations over long time periods using model free-runs. Instead it provides a validation in the type of system in which such parametrizations are most likely to be used, and it uncovers a number of issues which are specific to DA. However, it does also identify a number of fast-growing errors in some schemes, and these are important to both DA and free-running models.

\section{Ozone chemistry schemes}

\subsection{Photochemistry parametrization}

The rate of change of ozone due to photochemistry can be written (Cariolle and Déqué, 1986; McLinden et al., 2000; McCormack et al., 2006) as a first order Taylor expansion about the ozone production rate $(P)$ minus loss rate $(L)$, at an equilibrium state:

$$
\begin{aligned}
C= & (P-L)_{0}+\left.\frac{\partial(P-L)}{\partial \chi}\right|_{0}\left(\chi-\chi_{0}\right)+ \\
& \left.\frac{\partial(P-L)}{\partial T}\right|_{0}\left(T-T_{0}\right)+\left.\frac{\partial(P-L)}{\partial \Phi}\right|_{0}\left(\Phi-\Phi_{0}\right) .
\end{aligned}
$$

This parametrization has three variables: the local ozone mixing ratio, $\chi$ (in this paper as mass mixing ratio in units of $\mathrm{kg} \mathrm{kg}^{-1}$ ); the temperature, $T$, in $\mathrm{K}$, and the column of ozone overlying the level under consideration, $\Phi$, in $\mathrm{kgm}^{-2}$, where:

$\Phi=1 / g \int_{\mathrm{TOA}}^{l} \chi d p$,

and the integral runs over all pressure levels from the top of the atmosphere (TOA) down to level $l$, where $l$ is the level under consideration. All other items in Eq. (1) are coefficients valid at the equilibrium state (denoted with the subscript 0) which are either climatological values or have been pre-calculated with a detailed photochemical model. They are given as functions of latitude, model level and month; hence there is no diurnal or longitudinal variation. These include the equilibrium ozone production rate minus loss rate, $(P-L)_{0}$ and its partial derivatives, and the climatological values of ozone, $\chi_{0}$, temperature, $T_{0}$, and the overlying column of ozone, $\Phi_{0}$, which is calculated from vertical profiles of $\chi_{0}$ using Eq. (2).

The second term in the expansion accounts for variations in the local ozone amount, the third for temperature and the last term for the influence of non-local ozone on the amount of solar radiation reaching the level in question, and here we will call it the radiation term. 
Table 1. Linear ozone photochemistry coefficients.

\begin{tabular}{lll}
\hline Name & Notes & Reference \\
\hline $\begin{array}{l}\text { Cariolle v1.0 } \\
\text { Cariolle v1.2 }\end{array}$ & $\begin{array}{l}\text { As v1.0 but with heterogeneous } \\
\text { chem. term }\end{array}$ & $\begin{array}{l}\text { Cariolle and Déqué (1986) } \\
\text { Cariolle and Déqué (1986); Dethof and Hólm } \\
(2004)\end{array}$ \\
Cariolle v2 & & $\begin{array}{l}\text { Cariolle and Teyssèdre (2007) } \\
\text { LINOZ }\end{array}$ \\
Chem2D-OPP v0.1 & $(P-L)_{0}$ and ozone terms only & McLinden et al. (2000) \\
Chem2D-OPP v2 & All four terms & McCormack et al. (2004) \\
\hline
\end{tabular}

This photochemistry parametrization is primarily intended for use in the stratosphere. It causes no diurnal variation, but it should be remembered that there is in reality a diurnal cycle of ozone which starts to become significant at levels above $0.5 \mathrm{hPa}$, in the mesosphere. Also, the lack of longitudinal variation is not appropriate in the troposphere, where the surface sources of ozone precursors show strong temporal and spatial heterogeneity.

In the DARC implementation, the radiation term has been modified by substituting the following into Eq. (1):

$\Phi-\Phi_{0}=1 / g \int_{\text {TOA }}^{l}\left(\chi-\chi_{0}\right) d p$.

We have used Eqs. (2) and (3) to eliminate the overlying column climatology, $\Phi_{0}$, from the parametrization. Though it may seem trivial, this modification means that $\Phi$ and $\Phi_{0}$ are calculated implicitly using consistent methods. If they were not calculated consistently, the radiation term could produce a forcing even if $\chi=\chi_{0}$ throughout the overlying column. With this modification, $\Phi_{0}$ no longer needs to be recalculated from $\chi_{0}$ each time the model's vertical resolution changes. Neglecting to do this, and instead interpolating $\Phi_{0}$ to a new set of vertical levels, caused a $\sim 40 \%$ model bias in the lower mesosphere in the DARC/Met Office assimilation experiments examined in Geer et al. (2006a).

We can explore the effect of the parametrization by considering the ozone budget in a hypothetical model, which will include the rates of change (or tendency) of ozone due to modelled ozone transport, $A$, and chemistry, $C$ (from Eq. 1):

$$
\frac{\partial \chi}{\partial t}=A+C \text {. }
$$

If the temperature, overhead column ozone and transport ( $T$, $\Phi$ and $A$ respectively) are constant then we can define a steady state mixing ratio:

$\chi_{s s} \equiv \chi_{0}+\left[(P-L)_{0}+\left.\frac{\partial(P-L)}{\partial T}\right|_{0}\left(T-T_{0}\right)+\right.$

$$
\left.\left.\frac{\partial(P-L)}{\partial \Phi}\right|_{0}\left(\Phi-\Phi_{0}\right)+A\right] \tau,
$$

and the photochemical relaxation time,

$\tau \equiv-1 /\left(\left.\frac{\partial(P-L)}{\partial \chi}\right|_{0}\right)$.

This allows us to solve Eq. (4) analytically, showing that with steady-state transport and constant temperature and radiation terms, the linearised ozone photochemistry scheme will cause modelled ozone to follow an exponential relaxation to steady state, $\chi_{s s}$, with a time constant $\tau$ :

$\chi^{t+\Delta t}=\chi^{t}+\left(\chi_{s s}-\chi^{t}\right)\left(1-e^{-\Delta t / \tau}\right)$,

Ozone amounts $\chi^{t}$ and $\chi^{t+\Delta t}$ apply at times $t$ and $t+\Delta t$ respectively. Equations (5), (6) and (7) are similar to those derived in McLinden et al. (2000) and McCormack et al. (2006). However, the steady state (Eq. 5) is different here, because the effects of transport have been included.

Figure 1 shows the October value of $\tau$, the photochemical relaxation time, from the Cariolle v1.0 parametrization. In the upper stratosphere, outside the polar night, $\tau$ is less than a day and the ozone fields are essentially in photochemical equilibrium. If perturbed away from this equilibrium, ozone fields will quickly relax back to it. Lower in the stratosphere, photochemical relaxation times are much longer, with $\tau>100$ days at $100 \mathrm{hPa}$. Here, modelled transport has an important control over the ozone field.

When temperature and overhead column ozone are in their climatological state, i.e. $T=T_{0}$ and $\Phi=\Phi_{0}$, the steady state mixing ratio can be simplified:

$\chi_{s s}=\chi_{0}+\left[(P-L)_{0}+A\right] \tau$.

Equation (8) encapsulates the climatological balance between photochemistry and transport. If the steady state ozone amount generated by the photochemistry scheme is to be equal to climatological ozone, $\chi_{0}$, Eq. (8) requires either that modelled ozone transport must balance the net equilibrium production or loss due to photochemistry (i.e. 


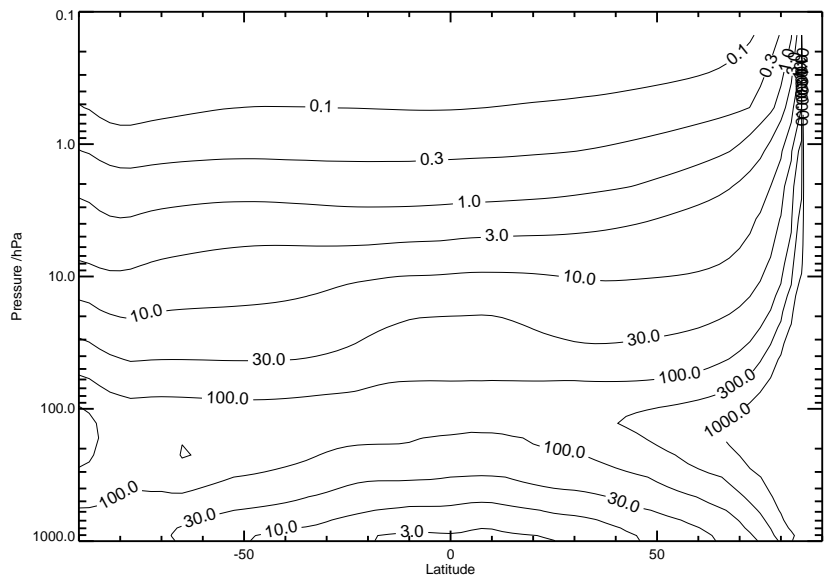

Fig. 1. October values of $\tau$, the photochemical relaxation time, in days, from the Cariolle v1.0 parametrization.

$\left.(P-L)_{0}+A=0\right)$, or that $\tau \rightarrow 0$. Hence in this example, ozone will always be close to climatology in regions where the photochemical relaxation time is short. In the mid and lower stratosphere and troposphere, relaxation times are relatively long (Fig. 1). Here, the steady-state example reflects real-life behaviour: In the lower stratosphere, for example, net photochemical production in the tropics is approximately balanced by the upward and poleward transport of ozone in the Brewer-Dobson circulation (e.g., Plumb et al., 2002); there is a net photochemical loss at higher latitudes.

\subsection{Practical considerations}

In the case of the radiation term, we have already seen that an incorrectly implemented linear photochemistry scheme can generate a spurious photochemical tendency (Eq. 3 and following discussion). The same principle applies to the other terms in the photochemistry scheme.

Equations (7) and (8) show that if modelled ozone transport $A$ does not balance the equilibrium photochemical tendency $(P-L)_{0}$, modelled ozone will relax toward a steady state $\left(\chi_{s s}\right)$ that is different from climatology $\left(\chi_{0}\right)$. If we denote the imbalance as an ozone tendency $\epsilon$ then that steady state would be:

$\chi_{s s}=\chi_{0}+\epsilon \tau$.

If modelled ozone transport were different from climatology because of natural variability, of course this would be a desirable result. However, particularly in data assimilation systems, stratospheric constituent transport can be erroneously fast (e.g., Schoeberl et al., 2003). Equation (9) shows that errors in the ozone tendency, or in transport, have most effect on modelled ozone where the photochemical relaxation time $\tau$ is relatively long, i.e. in the mid and lower stratosphere. Geer et al. (2006b) showed how an excessively fast modelled
Brewer-Dobson circulation caused biases in the DARC/Met Office ozone analyses in the mid stratosphere.

In the troposphere, it is important to account for ozone transport by convection and boundary layer processes. In the CTM used to generate the photochemistry coefficients, these processes may be parametrized through the use of vertical diffusion. In the GCM in which the ozone photochemistry parametrization is to be used, convection and boundary layer processes will be more explicitly resolved, though still heavily parametrized. If modelled transport $A$, differs between the CTM and the GCM, the equilibrium photochemical tendency $(P-L)_{0}$ will be consistent with the CTM, but not the GCM. Again, this could cause ozone amounts to be biased in the GCM.

In data assimilation applications it is necessary that model and observations should be unbiased with respect to one another. If the model were relaxing to steady state (Eq. 7), would this state be unbiased with respect to the climatology of assimilated ozone observations? It is usual to find small biases between different instruments and different climatologies. Hence, it is typical in data assimilation applications (e.g., Eskes et al., 2003) to use a new ozone climatology $\left(\chi_{0}\right)$ in place of the one supplied with the photochemistry scheme. It is hoped that the new climatology will be less biased with respect to observations. Often, as in this study, the Fortuin and Kelder (1998) climatology is chosen. Later we suggest that it may actually be necessary to use a climatology based on the observations being assimilated.

Similar considerations apply to the temperature climatology. If climatological mean temperatures in the model were different from those used in the photochemistry scheme, $T_{0}$, the temperature term (see Eq. 1) would on average produce a net forcing in ozone, with a consequent effect on the steady state (Eq. 5). Even if climatological transport and photochemistry were balanced $\left((P-L)_{0}+A=0\right)$, and overhead column ozone was in its equilibrium state $\left(\Phi=\Phi_{0}\right)$, the model would relax to a steady state that would be different from climatology. If the erroneous forcing were denoted $\epsilon$ then Eq. (9) would again apply.

Figure 2 compares the monthly mean analysed temperature for October 2003 to $T_{0}$ from three of the chemistry schemes used here. The climatologies and the DARC/Met Office analyses show differences of up to $20 \mathrm{~K}$. Between 6 and $30 \mathrm{hPa}$ at $80^{\circ} \mathrm{S}$ there is a warm bulge in Met Office temperatures, compared to climatology, and this is likely due to the strong minor warming that took place during October 2003 (Lahoz et al., 2006, see also Fig. 13). Randel et al. (2004) found that the CIRA86 climatology, as used in Chem2D-OPP v2.1, has a 5-10 K warm bias through much of the stratosphere. This is consistent with the positive bias seen in CIRA86 temperatures in Fig. 2, compared to the other climatologies, particularly around the stratopause.

The results later in this paper illustrate the problems that can be caused by discrepancies between the parametrization's ozone $\left(\chi_{0}\right)$ and temperature $\left(T_{0}\right)$ climatologies and the 

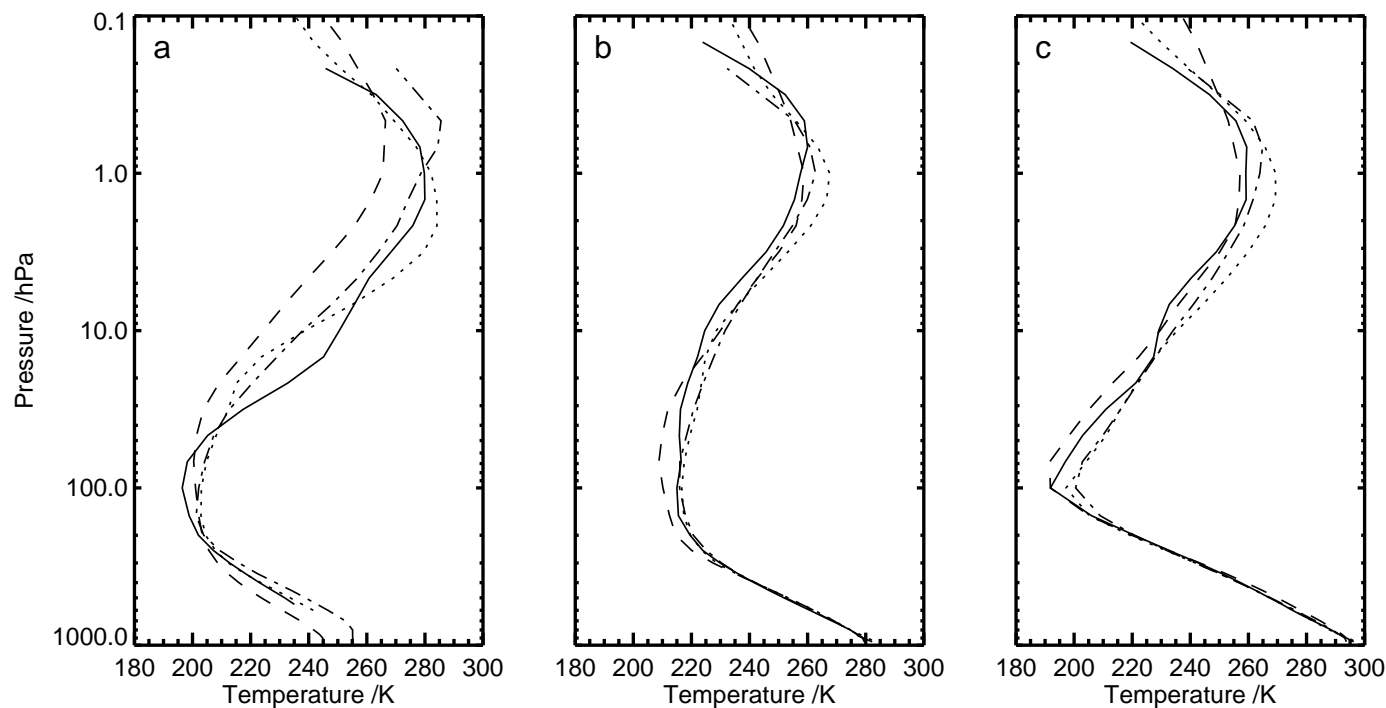

Fig. 2. October mean temperature at (a) $80^{\circ} \mathrm{S}$, (b) $40^{\circ} \mathrm{S}$, (c) the Equator, from the October 2003 DARC/Met Office analyses (solid), the Cariolle v1.0 (dot-dashed) and v2.1 (dashed) coefficients, and CIRA 1986 climatology used in Chem2D OPP v2.1 (dotted).

modelled or observed equivalents. However, a more careful choice of $\chi_{0}$ and $T_{0}$ will likely improve analysed ozone distributions. In contrast, there is no easy solution to the problem of erroneous or mis-matched ozone transport; this particularly affects modelled lower stratosphere ozone amounts. Data assimilation can correct the ozone distribution here, but not the underlying model errors.

\subsection{Heterogeneous chemistry}

Heterogeneous ozone chemistry must be modelled in order to describe ozone depletion in the spring polar vortex (e.g. WMO, 2003). In all experiments, heterogeneous chemistry is parametrized by a cold tracer scheme similar to that introduced by Hadjinicolaou et al. (1997). The focus here is on photochemistry, and the heterogeneous chemistry is kept fixed.

The cold tracer parametrization used here (P. Braesicke, personal communication) imposes an additional forcing on the ozone field to simulate the heterogeneous depletion of ozone:

$\left.\frac{d \chi}{d t}\right|_{h e t}=\frac{-1}{\eta} b \chi$

Here, $\eta$ is a time constant for heterogeneous ozone depletion, set to 10 days, and $b$ is the cold tracer, an advected 3-D field. The forcing is applied only in direct sunlight (solar zenith angle $<90^{\circ}$ ). The cold tracer represents the degree of chlorine activation; its chemical evolution is described by:

$\left.\frac{d b}{d t}\right|_{\text {chem }}=\frac{1}{\eta_{P}}(1-b)-\frac{1}{\eta_{L}} b$.
The first term on the right hand side is active only below a temperature threshold representative of polar stratospheric cloud (PSC) formation, $T_{P S C}$, and describes the rapid activation of heterogeneous chemistry with a time constant $\eta_{P}=4 \mathrm{~h} . T_{P S C}$ varies between $191.5 \mathrm{~K}$ at $26.5 \mathrm{~km}$ and $203 \mathrm{~K}$ at $11.5 \mathrm{~km}$. The term is switched off outside this altitude range, and equatorward of $55^{\circ}$. The second term is active only in direct sunlight and describes the slow loss of chlorine activation with a time constant of $\eta_{L}=10$ days in the southern hemisphere ( $\mathrm{SH})$ and $\eta_{L}=5$ days in the northern hemisphere (NH). Equation (11) implies that the cold tracer $b$ is bounded by 0 (representing no chlorine activation) and 1 (full activation). In practice, the cold tracer shows nearly full chlorine activation in the SH polar vortex in the lower stratosphere in our experiments for October 2003, with ozone depletion taking place only in sunlit areas.

A similar version of this scheme has been used succesfully in the KNMI (Royal Netherlands Meterological Institute) ozone data assimilation system (Eskes et al., 2003) and was able to make a good simulation of ozone depletion even without data assimilation (Siegmund et al., 2005). The Assimilation of Envisat Data (ASSET) intercomparison (Geer et al., 2006a) examined ozone analyses based on models with many different treatments of heterogeneous chemistry, including DARC/Met Office ozone analyses made with a system similar to that used here. The DARC/Met Office analyses performed adequately well in the ozone-hole, though amounts were not depleted to the near-zero values observed by sondes. This was due not to deficiencies in the cold tracer scheme, but instead to erroneous ozone production in the radiation term of the Cariolle v1.0 photochemistry scheme. Later we show that ozone depletion is well represented in the 
analyses when the cold tracer scheme is used with any of the other photochemistry parametrizations.

Cariolle and Teyssèdre (2007) have recently described two parametrizations of heterogeneous chemistry that may be used with v2 of their photochemistry scheme. The first one is a simple extra term in Eq. (1), active in sunlight at temperatures less than $195 \mathrm{~K}$, describing heterogeneous ozone depletion as proportional to the ozone amount. The second is a variant of the cold tracer technique. We do not test either of those parametrizations here, but Cariolle and Teyssèdre (2007) show that each parametrization is capable of representing polar ozone depletion in multi-annual model runs, with the cold tracer providing a longer maintenance of low ozone in the vortex, and additional export of ozone depletion to mid-latitudes. Geer et al. (2006a) have also shown that in assimilation experiments in the presence of good quality ozone observations, the Cariolle v2.1 chemistry scheme with the simple (non cold-tracer) heterogeneous parametrization is capable of producing results in the ozone hole similar to much more detailed treatments.

\subsection{Cariolle and Déqué (1986) v1.0, v2.1 and v2.8}

The Cariolle v1.0 scheme is described by Cariolle and Déqué (1986) and was calculated using a 2-D photochemical model with an upper boundary at $1 \mathrm{hPa}$, and by extrapolation or from 1-D model results above that level.

The subsequent v2 scheme is described by Cariolle and Teyssèdre (2007). It has been derived using the same 2-D photochemical model as for v1.0, though there have been a number of changes. Gas-phase chemical rates have been upgraded using the JPL (2003) recommendations, and total chlorine is set to year 2000 amounts. In contrast, v1.0 is based on knowledge of chemical rates and constituent amounts from the early 1980s. Another change in v2 is that the temperature distribution and the residual meridional circulation, used for minor tracer transport, are derived from a 10 year simulation of the Arpège-Climat general circulation model. This was found to be as important to the resulting coefficients as the change in chemical rates. The vertical and horizontal resolutions of the 2-D model have also been increased to match the Arpège-Climat discretisation. The 2-D model has 45 vertical levels extending up to $0.1 \mathrm{hPa}$, 64 latitudes, and accounts for the photochemistry of 63 species, 29 of which are transported.

The partial derivatives appearing in Eq. (1) are obtained by perturbing the 2-D model fields by $\pm 10 \%$ for the ozone mixing ratio (more precisely the odd oxygen family) and the ozone column, and by $\pm 10 \mathrm{~K}$ for the temperature. For each perturbed case the non-transported short lived species are reevaluated at steady state and the resulting ozone production and loss rates are used in the partial derivatives calculations. This is done for every month and a set of 7 zonal mean coefficients are obtained.
In our assimilation experiments we tested v2.1 of the Cariolle scheme. Close to publication, we were able to include the latest version, v2.8, but only in the offline comparisons presented in Sect. 2.7. There we see that v2.8 has improved accuracy in the upper stratosphere and mesosphere, and in the lower troposphere. Three configurations of the Cariolle parameters are tested with assimilation experiments: (a) using the supplied ozone climatology in the v2.1 scheme, (b) instead using Fortuin and Kelder (1998) climatology in the v2.1 scheme, and (c) using Fortuin and Kelder (1998) climatology in the v1.0 scheme.

Note that neither of the Cariolle v2 heterogeneous ozone depletion parametrizations are tested here; the cold tracer scheme described in Sect. 2.3 was used in all experiments.

\subsection{LINOZ}

The LINOZ scheme is described by McLinden et al. (2000). The coefficients in Eq. (1) were calculated for 12 months between $85^{\circ} \mathrm{S}$ and $85^{\circ} \mathrm{N}$ and and at 25 altitudes between 10 to $58 \mathrm{~km}$ using a photochemical box model (Prather and Jaffe, 1990; Prather, 1992). This model includes 109 kinetic reactions, 36 photolysis reactions and 43 species, and reaction coefficients and absorption cross-sections are adopted from DeMore et al. (1997). Species concentrations are characteristic of the 1990s (Avallone and Prather, 1997). For each monthly calculation, the box model is integrated for 30 days with the diurnal cycle fixed at mid-month. The ozone tendency and partial derivatives (see Eq. 1) are diurnally averaged.

Originally, the ozone and column ozone climatologies from McPeters (1993) and the temperature climatology from Nagatani and Rosenfield (1993) were used. Here instead we substitute the ozone climatology of Fortuin and Kelder (1998), consistent with the way LINOZ was used in ozone data assimilation experiments at KNMI (Eskes et al., 2003).

LINOZ coefficients are not available below $10 \mathrm{~km}$. Geer et al. (2006a) found that in the troposphere, a relaxation to ozone climatology produced smaller biases compared to ozonesonde than did the full linear chemistry parametrizations. Hence for LINOZ in these tests, below $10 \mathrm{~km}$, a relaxation to Fortuin and Kelder (1998) climatology was implemented, using the photochemical relaxation times of Cariolle v1.0.

\subsection{Chem2D-OPP v0.1, v2.1 and v2.6}

Chem2D-OPP is described by McCormack et al. (2004), for v0.1, and by McCormack et al. (2006) for v2; see http://uap-www.nrl.navy.mil/dynamics/html/chem2dopp/ chem2d_opp.html for updates. Photochemistry coefficients are computed with the NRL-Chem2D middle atmosphere photochemical-transport model (Siskind et al., 2003). The Chem2D model domain extends from pole to pole and from the surface up to $p=2 \times 10^{-5} \mathrm{hPa}(\sim 122 \mathrm{~km}$ altitude), 
with 47 vertical levels. The middle atmospheric radiative heating, photochemistry, and transport are fully coupled. Chem2D photochemistry accounts for 54 chemical species and uses updated JPL (2003) reaction rates. Halogen species amounts are constant in the troposphere and are taken from WMO (2003); stratospheric amounts are model-determined after a 20 year spin-up with the troposphere as a boundary condition. Diurnally averaged photolysis rates are computed by averaging hourly values, and diurnally averaged reaction rate coefficients are derived from pre-computed night-day ratios of relevant species. Solar irradiance for calculating both photolysis and UV radiative heating is specified as a function of wavelength from $120-800 \mathrm{~nm}$, including Lyman- $\alpha$ and both the Schumann-Runge continuum and Schumann-Runge bands for $\mathrm{O}_{2}$ photolysis.

Chem2D-OPP v0.1 includes the first two terms from the right hand side of Eq. (1) and does not account for temperature or radiation effects (McCormack et al., 2004). Diurnally averaged values of the Chem2D net ozone tendency $(P-L)_{0}$ are computed for the 15 th day of each month. The partial derivative with respect to mixing ratio, $\left.\frac{\partial(P-L)}{\partial \chi}\right|_{0}$ in Eq. (1), is calculated as the negative inverse of the ozone photochemical relaxation time $\tau$. The latter is determined from the sum of individual loss rates involving reactions with $\mathrm{NO}_{\mathrm{x}}, \mathrm{Cl}_{\mathrm{x}}$, and $\mathrm{HO}_{\mathrm{x}}$. The results are tabulated as functions of latitude, pressure, and month and then interpolated onto a $10^{\circ}$ latitude grid at standard pressure levels from $1000-0.001 \mathrm{hPa}$.

Chem2D-OPP v2.1 includes all four of the terms in Eq. (1). The v2.1 $(P-L)_{o}$ and $\left.\frac{\partial(P-L)}{\partial \chi}\right|_{0}$ coefficients are computed as in Chem2D-OPP v0.1. To evaluate the temperature and column ozone coefficients, $\left.\frac{\partial(P-L)}{\partial T}\right|_{0}$ and $\left.\frac{\partial(P-L)}{\partial \Phi}\right|_{0}$, respectively, the Chem2D model computes $(P-L)_{0}$ for a given altitude, latitude, and time of year, then immediately repeats the calculation using identical model constituent fields and a perturbation in either temperature or overlying ozone column amount. In the temperature case, perturbations $(\Delta T)$ between $\pm 20 \mathrm{~K}$ are imposed and the entire chemical system is then solved with an iterative Newton-Raphson technique until the $(P-L)$ values converge to a new equilibrium state. Similarly, the coefficient $\left.\frac{\partial(P-L)}{\partial \Phi}\right|_{0}$ is evaluated by introducing ozone column perturbations $\Delta \Phi$ between $\pm 50 \%$ to the Chem2D UV transmission functions used to compute the $\mathrm{O}_{2}$ and $\mathrm{O}_{3}$ photolysis rates. For a more detailed description of this method see McCormack et al. (2006).

The Chem2D model uses fixed heating rates at the surface as a model boundary condition and so the radiative heating is not coupled to model ozone in the lowermost model levels. For implementation in the DARC system, the v2.1 radiation term was turned off below $500 \mathrm{hPa}$ as it was suspected it would not work well in the lower troposphere. Surface values of the v2.1 photochemical relaxation time were erroneously negative due to an error in the vertical interpolation scheme, and this would have caused a runaway growth in ozone amounts. To prevent this happening, $\tau$ was reset to $\sim+2$ days at the surface. The experiments in this paper

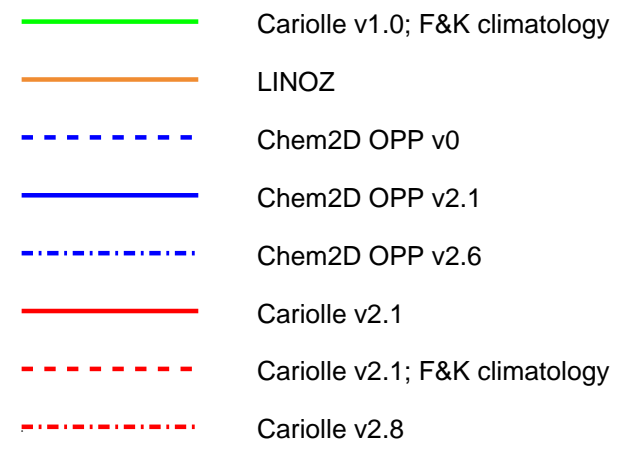

Fig. 3. Key to the parametrizations shown in Figs. 4 to 11.

also indicate a number of other discrepancies in v2.1. As for the Cariolle scheme, we were able at a late stage to examine the most recent Chem2D-OPP coefficients (v2.6), but again only in the offline comparisons. These comparisons show that most discrepancies have now been removed. Updated values for $\left.\frac{\partial(P-L)}{\partial \chi}\right|_{0}$, which now include $\mathrm{Br}_{\mathrm{x}}$ effects, provide shorter relaxation times in the lower stratosphere, bringing them closer to the Cariolle schemes.

\subsection{Offline comparison of photochemistry schemes}

We can examine the relative strengths of the terms in the different schemes by testing their sensitivity to a representative perturbation in ozone or temperature. For ozone, we used a perturbation based on the climatological ozone standard deviations of Fortuin and Kelder (1998), given as a function of month, pressure and latitude. For the overlying ozone column, we calculated the partial column integral of these standard deviations using Eq. (2). For temperature, we assumed a uniform perturbation of $5 \mathrm{~K}$, though around the wintertime polar vortex, stratospheric temperatures can vary by much larger amounts.

For each month, latitude and pressure level, the change in the net photochemical ozone tendency caused by the perturbation was normalised by the climatological ozone amount, $\chi_{0}$. For example, the sensitivity to changes in local ozone was calculated as:

$\Delta C=\left.\frac{\sigma_{\chi}}{\chi_{0}} \frac{\partial(P-L)}{\partial \chi}\right|_{0}$,

where $\sigma_{\chi}$ is the climatological ozone standard deviation. We then converted $\Delta C$ to units of $\%$ per day. The net climatological ozone tendency, $(P-L)_{0}$, was normalised by the climatological ozone amount so that it could be examined in the same units. The resulting sensitivities are shown for the months of January, April, July and October at the $50 \mathrm{hPa}$ level (Fig. 4) and the $5 \mathrm{hPa}$ level (Fig. 5).

It is clear from Figs. 4 and 5 that though the sensitivity of the coefficients can vary both zonally and from month to month, the major differences between the parametrizations 

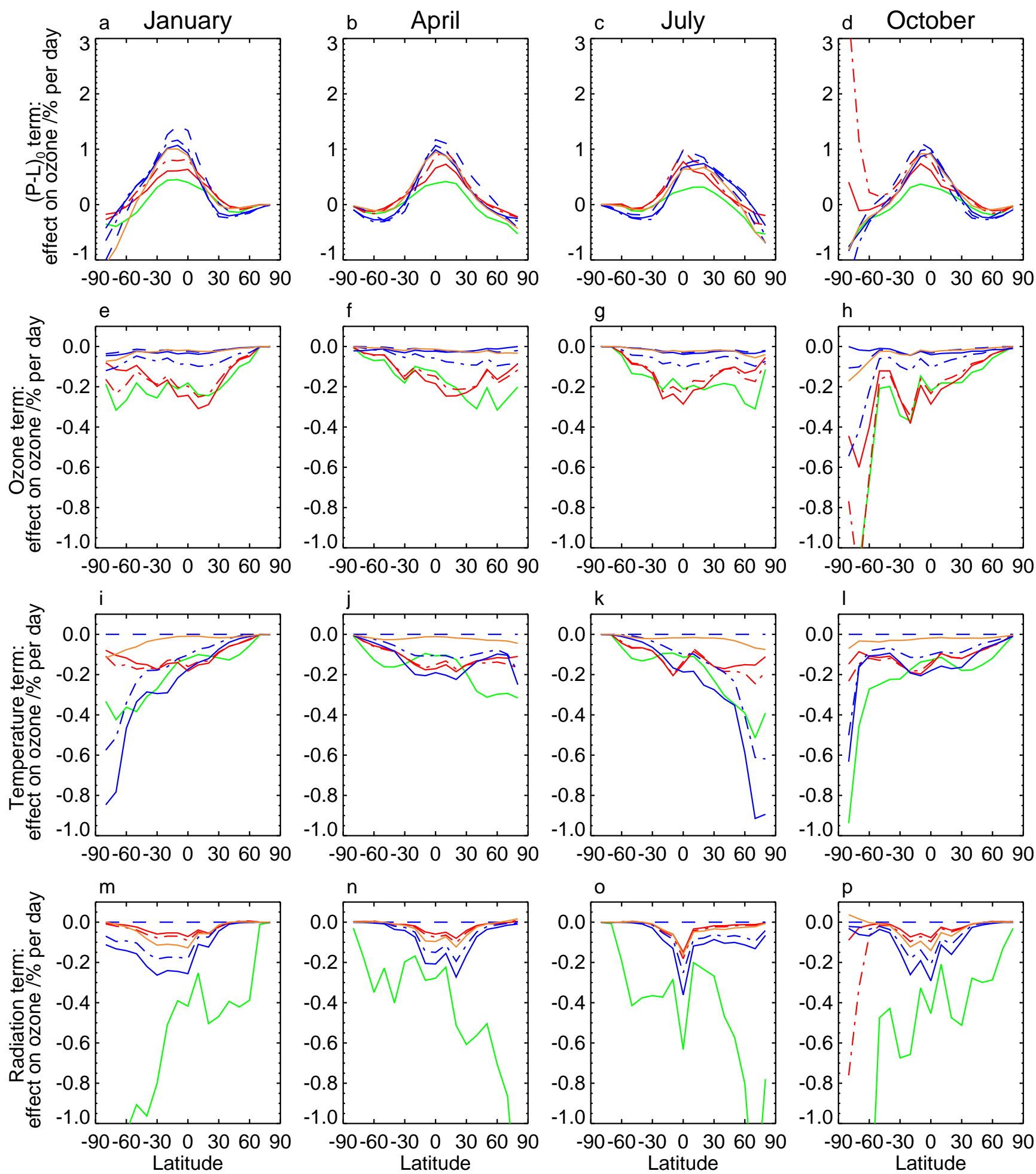

Fig. 4. Rate of change of ozone (\% per day) produced by the photochemistry schemes at the $50 \mathrm{hPa}$ level, from the $(P-L)_{0}$ term $(\mathbf{a}-\mathbf{d})$ and in response to typical perturbations of ozone $(\mathbf{e}-\mathbf{h})$, temperature $(\mathbf{i}-\mathbf{l})$, and overlying column ozone (m-p). Figures are shown for January (a, e, i, m), April (b, f, j, n), July (c, g, k, o) and October (d, h, 1, p). See colour key in Fig. 3. Note only one line is shown for Cariolle v2.1, because these values are independent of the climatology coefficients (in later figures we need to distinguish which ozone climatology was used). Note also that Chem2D-OPP v0.1 has no temperature or radiation term, so it shows zero sensitivity in those figures. 

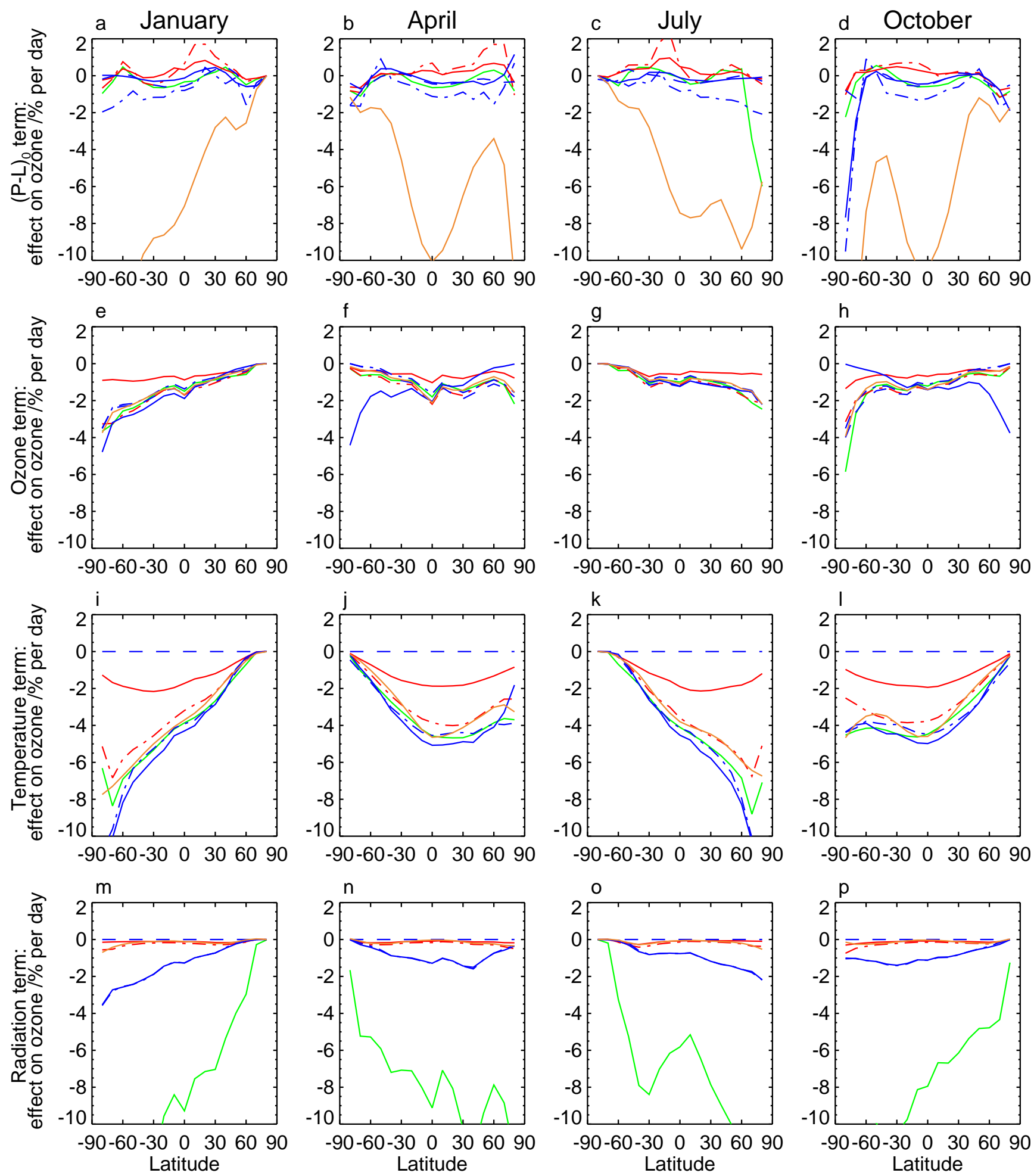

Fig. 5. As for Fig. 4, except at the $5 \mathrm{hPa}$ level. Note that in panels (m-p) the Chem2D-OPP v2.1 and v2.6 curves are superposed. 

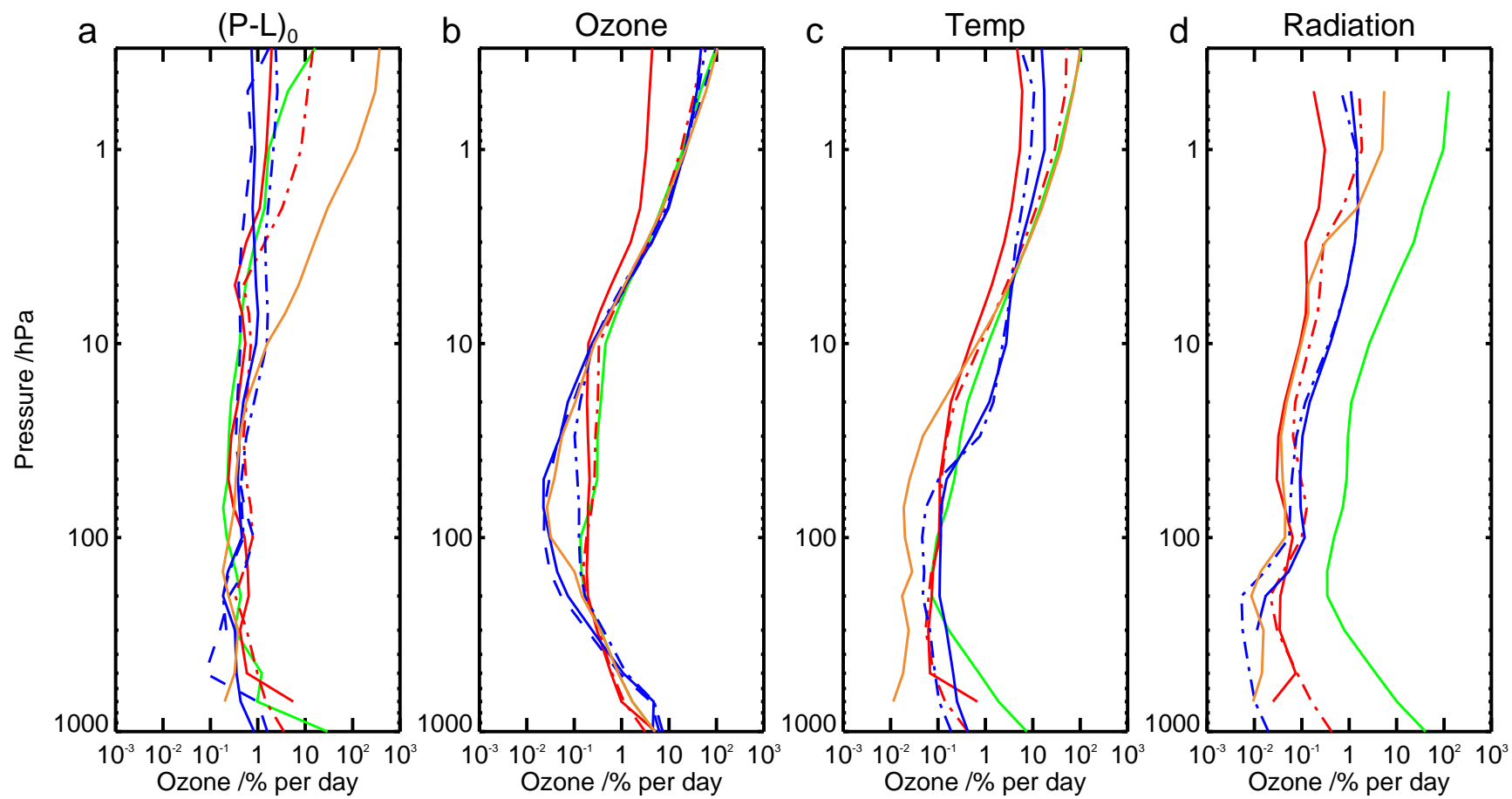

Fig. 6. Global mean absolute values of the rate of change of ozone (\% per day) produced by the October coefficients of the photochemistry schemes from the $(P-L)_{0}$ term (a) and in response to typical perturbations of ozone (b), temperature (c), and overlying column ozone (d). See colour key in Fig. 3. Note that zero rates of change cannot be shown on this figure because of the logarithmic scale; for example there is no line associated with the Chem2D-OPP v2.1 radiation term at $500 \mathrm{hPa}$ and below, where this term is set to zero.

are relatively consistent over all latitudes and months. To summarise Figs. 4 and 5 still further, and to extend this analysis to all vertical levels, we have calculated global means (equal weight by latitude) from the absolute value of $\Delta C$, for each pressure level and month. Figure 6 shows these global mean sensitivities for the month of October; other months are very similar (not shown). Because the figure shows global mean absolute sensitivities, there are no negative values. In general, the schemes have least influence on the ozone amount around the tropopause, and larger influence in the troposphere, upper stratosphere and mesosphere, where ozone photochemistry is faster. Of course, the relaxation times in Fig. 1 show a similar picture for the ozone term, but we are now able to compare between all terms in the parametrization.

Figures $4 \mathrm{a}-\mathrm{d}, 5 \mathrm{a}-\mathrm{d}$ and $6 \mathrm{a}$ show that outside the tropical lower stratosphere the $(P-L)_{0}$ term is small compared to the response of the other terms to representative perturbations. With the exception of LINOZ, and outside the lower troposphere, the magnitude of the $(P-L)_{0}$ term is similar in all schemes. At $50 \mathrm{hPa}$ (Figs. $4 \mathrm{a}-\mathrm{d}$ ), representative the lower stratosphere, there is a net ozone production in the tropics and net destruction in the higher latitudes, which should largely be balanced by ozone transport in the Brewer-Dobson circulation (see Sect. 2.1). In the tropics, net ozone pro- duction dominates over the other terms of the parametrization. At $5 \mathrm{hPa}$ (Figs. 5a-d, excepting LINOZ) the effect of the $(P-L)_{0}$ term hovers around zero net production. Here, and even more strongly at higher levels in the stratosphere, the other terms of the parametrization dominate over the $(P-L)_{0}$ term.

It is thought there may still be small discrepancies in our knowledge of photochemistry in the upper stratosphere, given the observed $\sim 10 \%$ ozone difference between models and observations (e.g. Natarajan et al., 2002). However, even if these discrepancies were to result in a small error in $(P-L)_{0}$ in the parametrizations tested here, its importance would be small: First because the sensitivities of the other terms in the parametrization are much larger (Fig. 6), and second because any error would be limited in its effect by the short relaxation times at these levels (Eq. 9).

Above $10 \mathrm{hPa}$, the LINOZ $(P-L)_{0}$ term is, erroneously, orders of magnitude larger than in the other schemes, and hence this has an effect despite the short relaxation times at these levels. Above $10 \mathrm{hPa}$, in LINOZ, this term causes a strong net loss of ozone, so large negative biases are generated above $10 \mathrm{hPa}$ (McCormack et al., 2004; Geer et al., 2006a).

Another likely error is that the $(P-L)_{0}$ terms in both Cariolle v1.0 and v2.1 are excessively large in the lower 
troposphere, being of order $10 \%$ per day (Fig. 6a). No accuracy is claimed for these schemes in the troposphere, but they should at least be well behaved. Later we see that such excessive net production results in relatively large ozone biases in the lower troposphere.

Figures $4 \mathrm{e}-\mathrm{h}, 5 \mathrm{e}-\mathrm{h}$ and $6 \mathrm{~b}$ show the sensitivity of the different parametrizations to ozone variations. To aid understanding, Fig. 7 shows the corresponding relaxation times (Eq. 6) at the equator. Note that there is no direct equivalence between the graphs: Figs. 4 to 6 depend on latitude-varying factors as well as the reciprocal of the relaxation time (see Eq. 12). The apparent discrepancy, for example at $5 \mathrm{hPa}$ at the equator in October, between relaxation times of 2 days (Fig. 7) and sensitivities of less than $2 \%$ per day (Fig. 5h), is explained by the climatological standard deviation, which is only $3 \%$ here.

Both the Cariolle v1.0 and v2.1 schemes are up to a factor of 10 more sensitive than LINOZ and Chem2D-OPP v0.1 and v2.1 to ozone variations in the lower stratosphere and at the tropopause. In terms of photochemical relaxation time, this corresponds to $\tau \sim 100$ days at the tropopause compared to $\tau$ approaching 1000 days in LINOZ and Chem2DOPP. This difference was noted by McCormack et al. (2004), though it is now thought that the rapid changes in ozone they found in Cariolle v1.0 hindcast experiments at high northern latitudes in the mid-stratosphere (around $10 \mathrm{hPa}$, their Fig. 11), which were attributed to the shorter relaxation time, were in fact most likely due to the very strong radiation term in Cariolle v1.0.

Version 2.6 of the Chem2D-OPP coefficients includes catalytic cycles involving bromine compounds $\left(\mathrm{Br}_{\mathrm{x}}\right)$, producing somewhat shorter values of $\tau$ in the lower stratosphere. We see that these values remain slightly longer than corresponding ones in the Cariolle v1.0 scheme. It must be noted that the Cariolle schemes and Chem2D-OPP use different methods to compute the relaxation time. In Cariolle's schemes it is computed after allowing for readjustment of the concentrations of short lived species in response to the ozone perturbation, whereas Chem2D-OPP takes an instantaneous value. In the middle and upper stratosphere where the ozone production is dominated by the photodissociation of $\mathrm{O}_{2}$ the two methods should converge. However, the two approaches may differ in the lower stratosphere where, for example, readjustments in the amount of $\mathrm{NO}_{\mathrm{x}}$ species will have a significant effect on ozone production. The validity of each approach would depend on the timescales of the perturbations: for fast perturbations the instantaneous approach should be valid; for perturbations with timescales longer than a day, the readjustment of minor species should be taken into account.

In the upper stratosphere and mesosphere, Cariolle v2.1 has relatively low sensitivity to typical ozone variability, compared to the other schemes. Equivalently, this means that photochemical relaxation times are substantially longer in Cariolle v2.1. This low sensitivity (extending also to the temperature and radiation terms) resulted from problems with

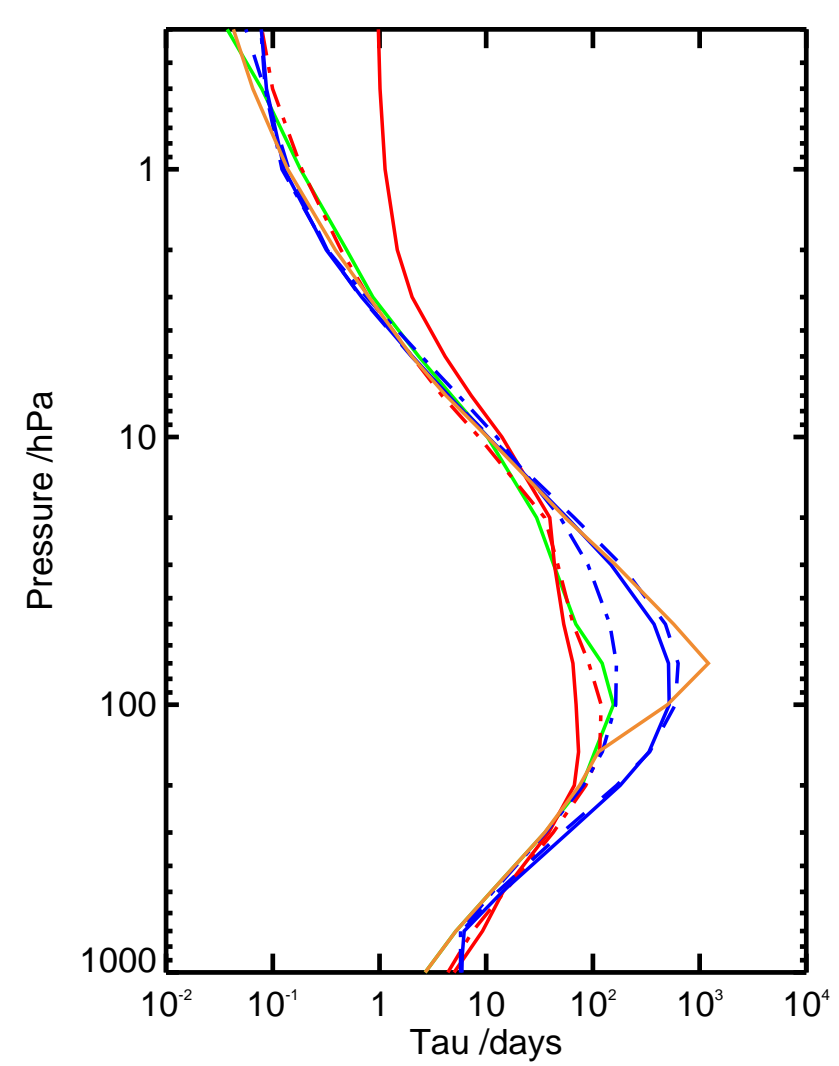

Fig. 7. October values of $\tau$, the photochemical relaxation time, at the equator, for each of the different parametrizations shown in the key in Fig. 3.

making semi-implicit calculations in regions with fast chemistry. The problem was fixed by using an explicit calculation, and we see that the resulting Cariolle v2.8 is very close to the majority of the other schemes.

Chem2D-OPP v2.1 shows problems near the poles in April and October (Figs. $5 \mathrm{f}$ and h). This was due to corrupted outputs from the Chem2D model, and has later been corrected: Chem2D-OPP v2.6 now agrees with the majority of the other schemes. However, this error is a main factor in causing problems in the south polar upper stratosphere in our assimilation experiments with Chem2D-OPP v2.1.

Figures $4 \mathrm{i}-1,5 \mathrm{i}-1$ and $6 \mathrm{c}$ show that there are few large discrepancies between the temperature terms of the different schemes, though differences up to an order of magnitude can be found in some areas.

Figure $4 m-p, 5 m-p$ and $6 d$ show that in the radiation term, the main outlier is the Cariolle v1.0, which is excessively strong compared to other schemes. It is not clear why the Cariolle v1.0 term should be so strong, since similar methods were used to create v1.0 and v2. Since the v1.0 coefficients were distributed many years ago it is not now possible to re-examine this in detail. The strong Cariolle v1.0 radiation term was responsible for the problem of excessive creation 
of ozone in the ozone hole described in Geer et al. (2006b) and the rapid ozone changes see in hindcast experiments at $10 \mathrm{hPa}$ by McCormack et al. (2004, their Fig. 11). The other schemes also show differences, typically of less than an order of magnitude, but we see that the influence of the radiation term is typically smaller than that of the ozone or temperature terms, so these differences are not particularly important.

In summary, the LINOZ $(P-L)_{0}$ term and the Cariolle v1.0 radiation term have sensitivities up to two orders of magnitude different from the equivalent terms in the other parametrizations. These erroneous coefficients lead to problems that have been seen in a number of studies (McCormack et al., 2004; Geer et al., 2006a,b). In the early versions of the most recent parametrizations, Cariolle v2.1 and Chem2D-OPP v2.1, there were discrepancies of up to 1 order of magnitude in some areas, compared to the other schemes. These discrepancies were in part due to erroneous calculations, but also in the lower stratosphere, relaxation times became shorter in Chem2D-OPP, and closer to Cariolle v2, after $\mathrm{Br}_{\mathrm{x}}$ chemistry was included. The latest schemes (Cariolle v2.8 and Chem2D-OPP v2.6) show only relatively minor remaining differences, likely resulting from the varied ways in which the coefficients have been derived.

\section{Method}

\subsection{Assimilation system}

The Met Office NWP system has recently been extended to allow the assimilation of ozone (Jackson and Saunders, 2002; Jackson, 2004) but ozone is not assimilated operationally. Here, MIPAS v4.61 ozone is assimilated in reanalysis mode, alongside all operational dynamical observations, using a stratosphere/troposphere version of the operational NWP system. The system is that described in Geer et al. (2006a), except that MIPAS temperatures are no longer assimilated, since it was found that their assimilation could degrade analysed stratopause temperatures. The GCM has a horizontal resolution of $3.75^{\circ}$ longitude by $2.5^{\circ}$ latitude and 50 levels in the vertical, from the surface to $\sim 0.1 \mathrm{hPa}$. It uses a new dynamical core (Davies et al., 2005) which includes a semi-Lagrangian transport scheme. The ozone tracer is subject to convective and boundary layer transport. There is no feedback between ozone and radiation: heating rate calculations are done using an ozone climatology. Data assimilation uses 3D-Var (Lorenc et al., 2000). Ozone is assimilated univariately, but 3D-Var does not infer dynamical information, so the only effect of ozone on the dynamical analysis is through its influence on temperature radiance assimilation.

\subsection{MIPAS}

MIPAS is an interferometer for measuring infrared emissions from the atmospheric limb (Fischer and Oelhaf, 1996). MIPAS operational data are available between July 2002 and
March 2004, after which instrument problems meant it could only be used on an occasional basis. The operational measurements were made along 17 discrete lines-of-sight in the reverse of the flight direction of ENVISAT, with tangent heights between $8 \mathrm{~km}$ and $68 \mathrm{~km}$. The vertical resolution was $\sim 3 \mathrm{~km}$ in the stratosphere and the horizontal resolution was $\sim 300 \mathrm{~km}$ along the line of sight. ENVISAT follows a sunsynchronous polar orbit, allowing MIPAS to sample globally, and to produce up to $\sim 1000$ atmospheric profiles per day. From the infrared spectra, ESA retrieved profiles of pressure, temperature, ozone, water vapour, $\mathrm{HNO}_{3}, \mathrm{NO}_{2}, \mathrm{CH}_{4}$ and $\mathrm{N}_{2} \mathrm{O}$ at up to 17 tangent points (ESA, 2004). MIPAS version 4.61 data, reprocessed offline, is used here. When treated as a point retrieval, MIPAS ozone has only small biases when compared to independent data except in the lower stratosphere (100 to $30 \mathrm{hPa}$ ), where positive biases of order $10 \%$ are seen (Geer et al., 2006a).

Apart from a small number rejected for quality control reasons, all available MIPAS ozone observations were assimilated into the Met Office NWP system in the experiments presented here.

\subsection{Experiments}

Table 2 summarises the ozone chemistry characteristics of the six assimilation experiments performed here, which were otherwise identical. Experiments were initialised on 23 September 2003 with fields from the DARC/Met Office analyses produced for the ASSET intercomparison and described in Geer et al. (2006a), and were run until 5 November 2003. The period was limited to six weeks by the computational expense of running the assimilation system. The strength of these assimilation experiments is that we can test the parametrizations under conditions of rapid synoptic variability. Hence the period was chosen for the rapid variability linked with the breakdown of the SH polar vortex and the development of the $\mathrm{NH}$ polar vortex. It also captures the time of the deepest extent of the ozone hole. Lahoz et al. (2006) describe the $2003 \mathrm{SH}$ winter and spring in more detail.

\subsection{Validation framework}

Analyses are compared to independent data from ozonesonde and HALOE, and also to the assimilated MIPAS observations, using the methods described in Geer et al. (2006a). Analyses are interpolated onto a set of fixed pressure levels and sampled daily at 00:00 $\mathrm{Z}$ and 12:00 Z, before being compared to observations. The independent observations are described briefly below; see Geer et al. (2006a) for further details. It is worth noting that MIPAS, sonde and HALOE have different temporal and spatial sampling. For example MIPAS sampled most latitudes daily; HALOE observations come from discrete latitude bands (see coverage plots in Geer et al., 2006a). Hence, some differences are to be expected 
Table 2. Summary of experiments.

\begin{tabular}{ccc}
\hline Name & Ozone climatology, $\chi_{0}$ & Heterogeneous chemistry \\
\hline Cariolle v1.0 with F\&K climatology & Fortuin and Kelder (1998) & Cold tracer \\
Cariolle v2.1 & Cariolle v2.1 & Cold tracer \\
Cariolle v2.1 with F\&K climatology & Fortuin and Kelder (1998) & Cold tracer \\
LINOZ & Fortuin and Kelder (1998) & Cold tracer \\
Chem2D-OPP v0.1 & Fortuin and Kelder (1998) & Cold tracer \\
Chem2D-OPP v2.1 & Fortuin and Kelder (1998) & Cold tracer \\
\hline
\end{tabular}

when comparing to different datatypes, simply because of the varying geographical and temporal coverage.

\subsubsection{Ozonesondes}

Ozonesondes are used as independent data to validate the analyses. Profiles have been obtained from the World Ozone and Ultraviolet Radiation Data Centre (WOUDC, http://www.woudc.org/), Southern Hemisphere Additional Ozonesondes project (SHADOZ, http://croc.gsfc.nasa.gov/ shadoz/, Thompson et al., 2003a,b) and the Network for the Detection of Stratospheric Change (NDSC, http://www.ndsc. ncep.noaa.gov/). We use all available ozonesonde ascents, except for the Indian sondes as they have large errors. No other selection criteria were applied. The data used come from 42 locations and were made using a variety of measurement techniques. Sondes typically make measurements from the surface to around the $10 \mathrm{hPa}$ level. Total error for the most common type of ozonesonde is estimated to be within $-7 \%$ to $+17 \%$ in the upper troposphere, $\pm 5 \%$ in the lower stratosphere up to $10 \mathrm{hPa}$ and $-14 \%$ to $+6 \%$ at $4 \mathrm{hPa}$ (Komhyr et al., 1995). Errors are higher in the presence of steep ozone gradients and where ozone amounts are low.

\subsubsection{HALOE}

HALOE (Russell et al., 1993) is used as independent data to validate the analyses. HALOE uses solar occultation to derive atmospheric constituent profiles, making the data sparse in time and space, with about 15 observations per day at each of two latitudes. The horizontal resolution is $495 \mathrm{~km}$ along the orbital track and the vertical resolution is about $2.5 \mathrm{~km}$. We use a version 19 product, screened for cloud using the algorithm of Hervig and McHugh (1999), and available from the HALOE website (http://haloedata.larc.nasa.gov/). Version 19 ozone retrievals are nearly identical to those of $\mathrm{v} 18$, and above the $120 \mathrm{hPa}$ level they agree with ozonesonde data to within 10\% (Bhatt et al., 1999). Below this level, profiles can be seriously affected by the presence of aerosols and cirrus clouds.

\section{Results}

Figures 8, 9 and 10 show, respectively, the mean differences between analyses and HALOE, sonde and MIPAS observations, given as a percentage relative to an ozone climatology. This ozone climatology is described in Geer et al. (2006a) and combines those of Fortuin and Kelder (1998) and Logan (1999). Statistics are calculated for the period 27 September 2003 to 5 November 2003

In the troposphere, upper stratosphere and mesosphere, and polar vortex, there are differences between experiments. Here, biases between analyses and independent data can in general be attributed to the ozone photochemistry schemes. In the lower stratosphere (100 to $10 \mathrm{hPa})$, away from the ozone hole, biases are unconnected with the photochemistry schemes. Geer et al. (2006a) show that positive biases of up to $20 \%$ against sonde and HALOE are likely explained both by the small $(\sim 10 \%)$ positive bias in MIPAS in these regions, and by poor quality transport, a known deficiency in stratospheric data assimilation systems. These biases are a particular problem at the tropical tropopause, where the DARC/Met Office analyses are 50\% higher than ozonesondes. Similar biases were found in many ozone analysis systems, though the DARC/Met Office analyses have an atypically large bias at the tropopause. Biases against HALOE and MIPAS at $100 \mathrm{hPa}$ and below should be treated with much caution due to possible cloud contamination of the observations; ozonesondes are much more reliable here.

We also examined the standard deviations of difference between analyses and observations. The results were in general very similar to those seen in Geer et al. (2006a), and typical of many ozone data assimilation systems. Significant differences between experiments were found only in the $\mathrm{SH}$ high latitude upper stratosphere, shown in Fig. 11. HALOE and MIPAS have different sampling patterns (e.g. Geer et al., 2006a); this is the most likely reason for differences between the two panels of Fig. 11.

The following sections examine these biases and standard deviations at different levels in the atmosphere. 

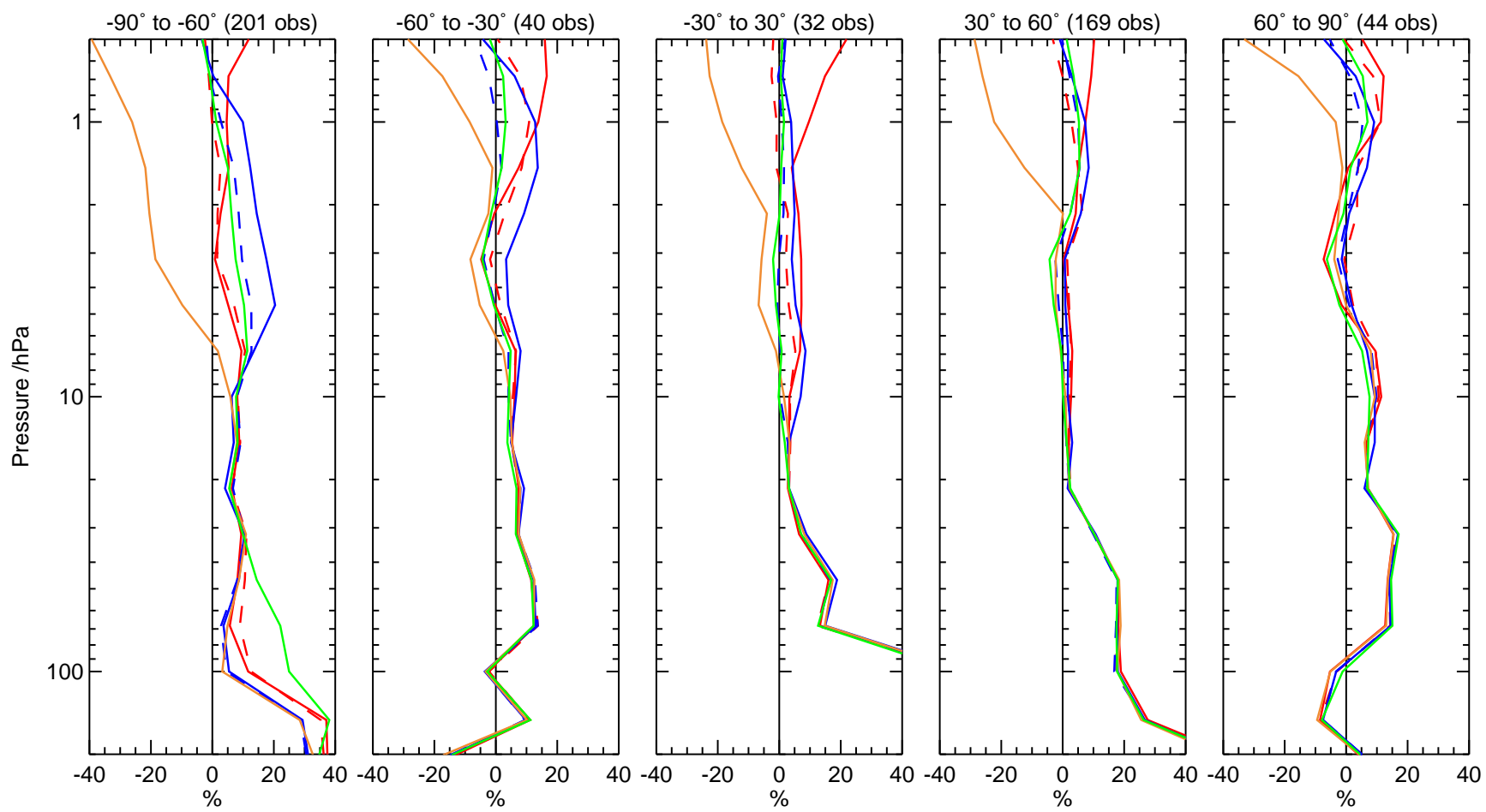

Fig. 8. Mean of (analysis - HALOE) ozone, normalised by climatology, in latitude bands for the period 27 September 2003 to 5 November 2003. Vertical scale ranges from $200 \mathrm{hPa}$ to $0.5 \mathrm{hPa}$. See colour key in Fig. 3.
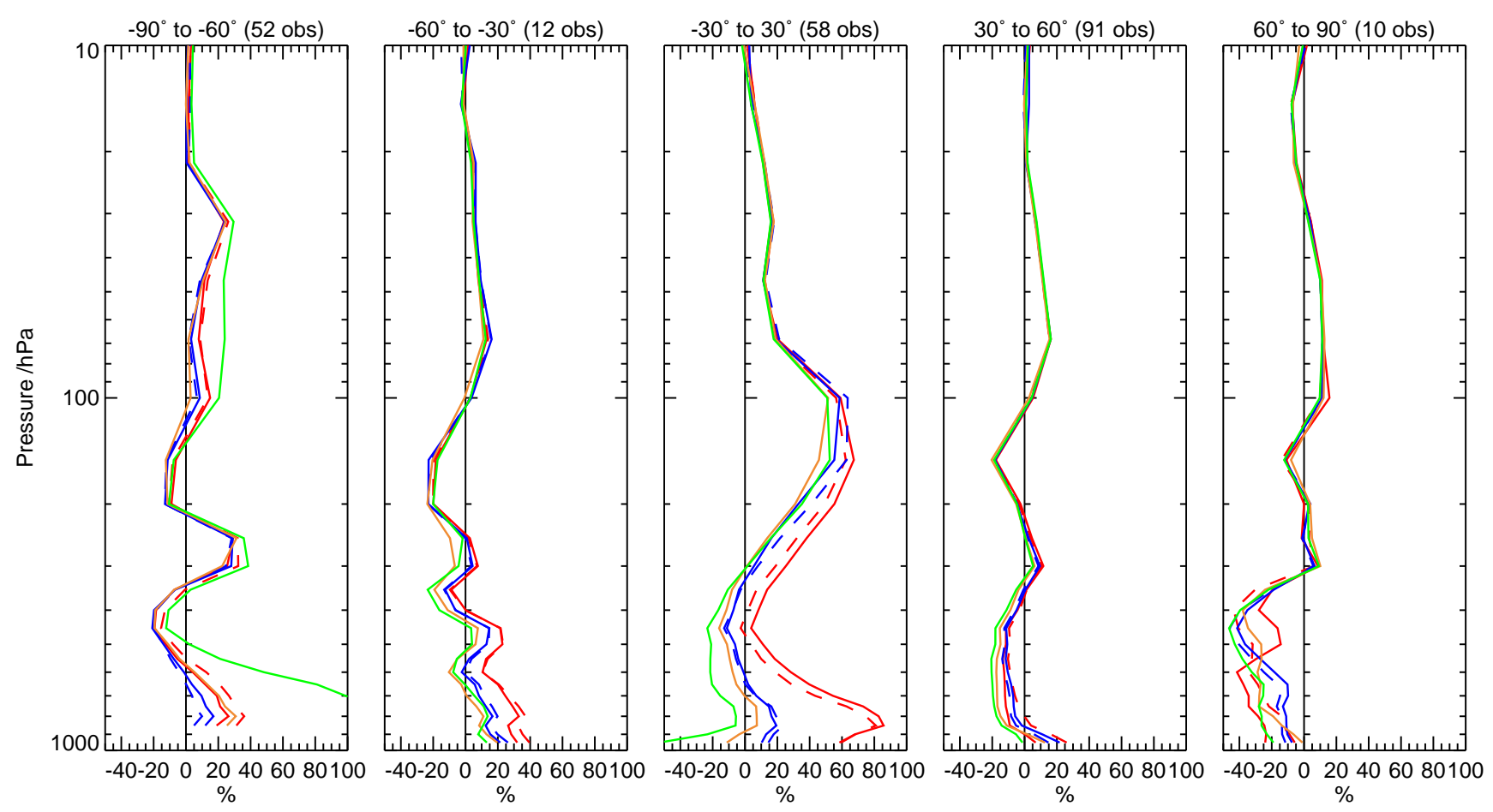

Fig. 9. Mean of (analysis - ozonesonde) ozone, normalised by climatology, in latitude bands for the period 27 September 2003 to 5 November 2003. Vertical scale ranges from $1000 \mathrm{hPa}$ to $10 \mathrm{hPa}$ (ozonesondes do not usually produce data above this level). See colour key in Fig. 3. 

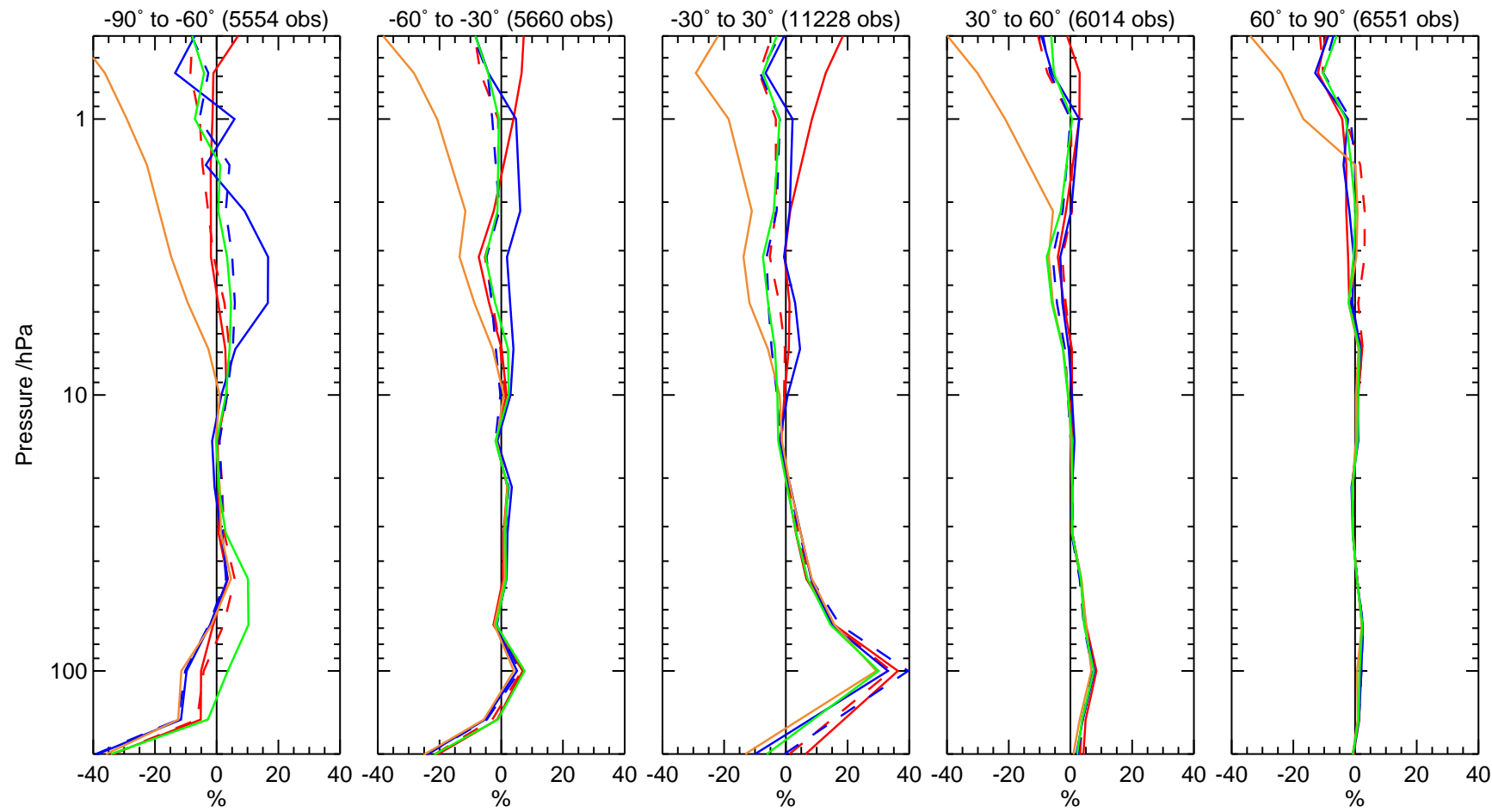

Fig. 10. Mean of (analysis - MIPAS) ozone, normalised by climatology, in latitude bands for the period 27 September 2003 to 5 November 2003. Vertical scale ranges from $200 \mathrm{hPa}$ to $0.5 \mathrm{hPa}$. See colour key in Fig. 3.

\subsection{Upper stratosphere and mesosphere}

In the upper stratosphere and mesosphere, the LINOZ scheme produces negative ozone biases that reach roughly $40 \%$ at $0.5 \mathrm{hPa}$ (Figs. 8 and 10). This is a known problem with the scheme (McCormack et al., 2004; Geer et al., 2006a), which is caused by an excessive net loss of ozone driven by a $(P-L)_{0}$ term that is up to several orders of magnitude larger than that in the other schemes in this region (Sect. 2.7, Fig. 6). Despite such large differences, the resulting biases are no more than $\sim 40 \%$ of the ozone field. Why should this be? Equation (7) showed that the ozone parametrization causes a relaxation to steady state that is particularly strong in the upper stratosphere and mesosphere. In Sect. 2.2 we saw that an error $\epsilon$ in the ozone tendency would lead to a steady state different from climatology: $\chi_{s s}=\chi_{0}+\epsilon \tau$. However, because the photochemical relaxation time $\tau$ is very short at these levels, the impact of the error is comparatively small. If we assume the other parametrizations are correct then we can estimate the error in the LINOZ $(P-L)_{0}$ term from Fig. 6 as of order $500 \%$ per day at $0.5 \mathrm{hPa}$. From Fig. 7, the corresponding relaxation time at $0.5 \mathrm{hPa}$ is of order 0.1 days. Hence we would expect an error in ozone of around 50\%, in agreement with Figs. 8 and 10.

There are positive biases in Chem2D-OPP v2.1 analyses in the upper stratosphere ( $1 \mathrm{hPa}$ to $10 \mathrm{hPa})$, reaching $20 \%$ in
SH high latitudes, compared both to MIPAS and HALOE. In the same region, Chem2D-OPP v2.1 shows the largest standard deviations against MIPAS and HALOE of any of the analyses, reaching 20\% against MIPAS (Fig. 11), though in other latitude bands (not shown) there is little difference between experiments. Figure 12 shows examples of the analysed ozone fields at $3.2 \mathrm{hPa}$. It appears that, at latitudes $60^{\circ} \mathrm{S}$ to $90^{\circ} \mathrm{S}$, Cariolle v2.1 represents the observed ozone field quite realistically, with standard deviations of $\sim 6 \%$ against HALOE and MIPAS (Fig. 11). In contrast, Cariolle v1.0 and Chem2D-OPP v0.1 have standard deviations of $\sim 10 \%$, suggesting that the smaller range of ozone values in these analyses over the poles (Fig. 12) is less in agreement with independent data. Structure seen in the ozone field over the pole in the Chem2D v2.1 analyses is likely erroneous, given the much larger ( 20\%) standard deviations.

The primary explanation for the erroneous structure in the Chem2D-OPP v2.1 ozone fields is the excessively long relaxation times near the South Pole in October (shown as very low sensitivities in Fig. 5h). This allows the temperature term to dominate, but the temperature term in Chem2D-OPP v2.1 also has problems. We have already seen that the CIRA86 temperature climatology used with Chem2D is substantially different from the modelled temperatures (Fig. 2). During the vortex breakup, temperature structures are often far from zonal mean, as can be seen from Fig. 13. Examination of 

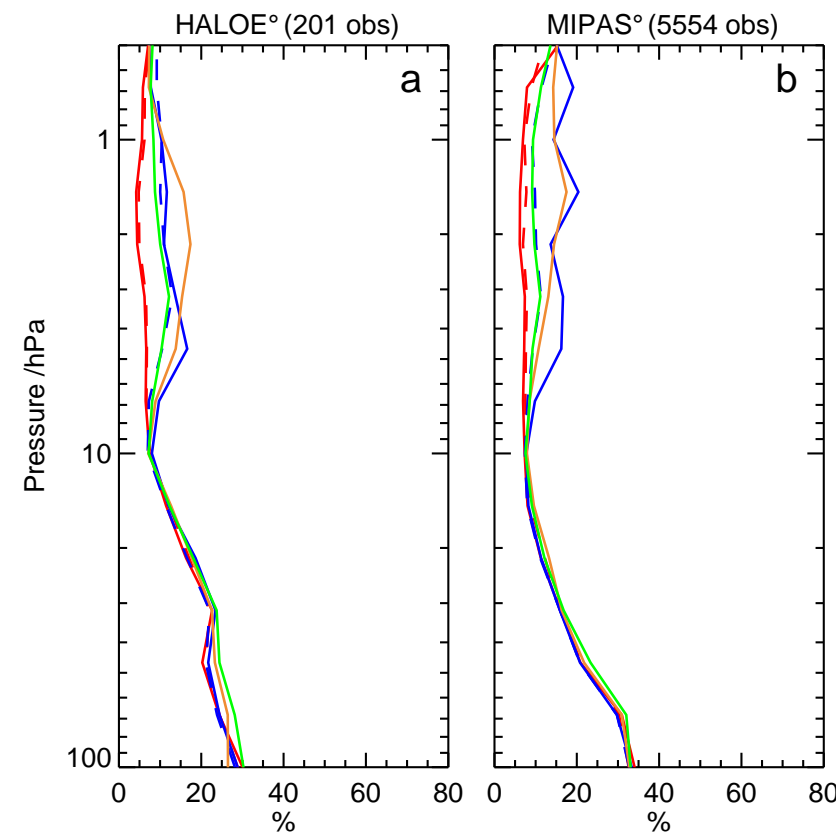

Fig. 11. Standard deviation of (a) (analysis - HALOE) and (b) (analysis - MIPAS) ozone, normalised by climatology, in the latitude band $90^{\circ} \mathrm{S}$ to $60^{\circ} \mathrm{S}$ for the period 27 September 2003 to 5 November 2003. See colour key in Fig. 3.

the individual terms shows that the strongly non-zonal temperature field causes the temperature term in Eq. (1) to drive ozone amounts away from the zonal mean. The influence of the radiation and $(P-L)_{0}$ terms is relatively weak. Opposition to the temperature term comes mainly from the ozone term, which returns ozone amounts to zonal mean, but this is erroneously weak (Fig. 5h). Additionally, these experiments show that data assimilation increments are not able to improve the ozone field where the temperature term is so strong: it can produce changes of ozone of $10 \%$ in a day with just a $5 \mathrm{~K}$ perturbation from climatology (see Fig. $6 \mathrm{c}$ above $5 \mathrm{hPa}$ ).

McCormack et al. (2006) have also identified problems with the temperature term in model-only runs using Chem2D-OPP. Particularly in the polar night, where the ozone term is weak, discrepancies between modelled and CIRA86 climatology temperatures were seen to cause problems.

Cariolle v2.1 shows positive biases (Figs. 8 and 10) at $1 \mathrm{hPa}$ and above, reaching a maximum of $20 \%$ in the tropics at $0.5 \mathrm{hPa}$. Biases against both HALOE and MIPAS are typically smaller, though not eliminated, when the Fortuin and Kelder (1998) climatology is used instead of the supplied climatology. This suggests that the climatology supplied with the Cariolle v2.1 scheme is slightly biased at these levels, and that replacing it with the Fortuin and Kelder (1998) climatology can remove part of this bias. However, even after doing this, there are still biases of order $10 \%$ in the analyses

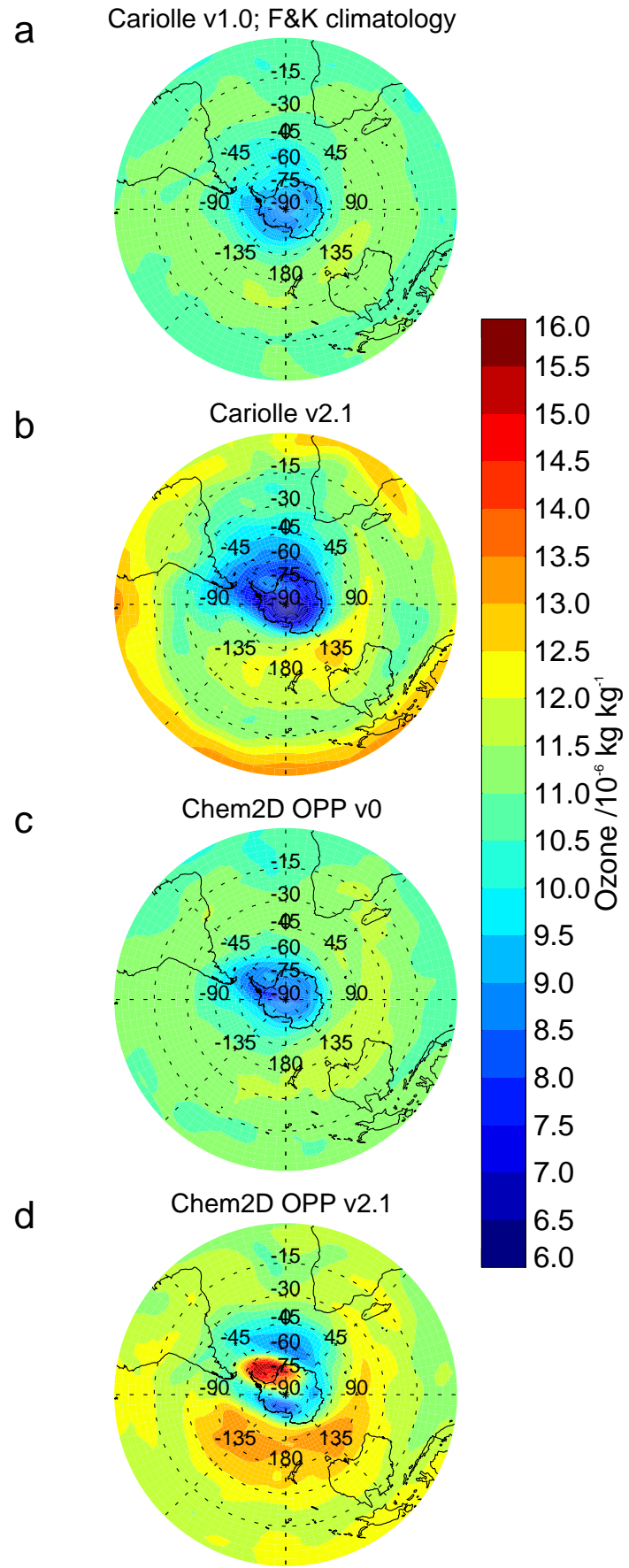

Fig. 12. Ozone fields at $3.2 \mathrm{hPa}$ on 1 October 2003 from (a) Cariolle v1.0, (b) Cariolle v2.1, (c) Chem2D-OPP v0.1 and (d) Chem2D-OPP v2.1 analyses.

versus HALOE. Section 2.7 has shown that the temperature and ozone terms in Cariolle v2.1 are excessively weak in the upper stratosphere and mesosphere. However, the relaxation time is still roughly a day (Fig. 7) at these levels, and so it still causes a rapid relaxation to climatology. Following 
the arguments in Sect. 2.2, it is likely the biases could be further reduced by fine-tuning the temperature climatology $\left(T_{0}\right)$ and making the ozone climatology $\left(\chi_{0}\right)$ consistent with climatological ozone amounts from MIPAS. However, MIPAS and HALOE are biased by $\sim 5 \%$ with respect to each other at these levels (Geer et al., 2006a), so even if the model was consistent with MIPAS, there would necessarily be a bias compared to HALOE. Moreover, this would improve the simulation for the period studied without guarantee of its applicability for other seasons.

In summary, in the upper stratosphere and mesosphere, LINOZ is unsuitable for use, and there are regional biases in the Cariolle v2.1 and Chem2D-OPP v2.1 experiments (respectively, the tropical mesosphere and the upper stratospheric winter vortex). The Cariolle v2.1 biases would likely be reduced by further attention to the temperature and ozone climatologies, $T_{0}$ and $\chi_{0}$, as well as by use of the improved v2.8 coefficients (Sect. 2.7). Chem2D-OPP v2.1 has erroneously long relaxation times in the south polar upper stratosphere in October, but this problem has been removed in v2.6. Excluding LINOZ, and Cariolle v2.1 and Chem2D v2.1 in the problem regions, analyses show biases in the range $-10 \%$ to $10 \%$.

\subsection{Lower stratosphere}

At SH high latitudes at the levels where ozone depletion takes place in the ozone hole (100 to $40 \mathrm{hPa}$ ), the Cariolle v1.0 experiment shows roughly $20 \%$ too much ozone compared to HALOE and sonde. As explained in more detail in Geer et al. (2006b), the strong radiation term of the v1.0 parametrization (Fig. 6d) creates erroneously large amounts of ozone in the ozone hole. The other experiments show positive biases of no more than $10 \%$, confirming that they work well in conjunction with the cold tracer heterogeneous chemistry scheme. The biases against MIPAS are smaller still, indicating that the analyses have drawn close to the assimilated MIPAS observations and the remaining biases against independent data reflect the $\sim 10 \%$ positive bias between MIPAS and independent data in these regions (Geer et al., 2006a).

At the tropical and midlatitude tropopause, comparisons against independent data show no difference between experiments. This is despite an order of magnitude difference in the sensitivity of the ozone terms in Cariolle v2.1 and Chem2DOPP v2.1 (Fig. 6b). Photochemical relaxation times are in both cases extremely long ( $~ 100$ days and $\sim 1000$ days, respectively; see Fig. 7). In a data assimilation system, the chemistry scheme will be only a minor part of the ozone budget here, which will instead be dominated by observational increments. Hence, evaluation within a data assimilation system is not able to distinguish between the parametrizations or to suggest which may be more correct. Differences would only appear in relatively long free-model runs, which would also require a very good representation of tracer transport.

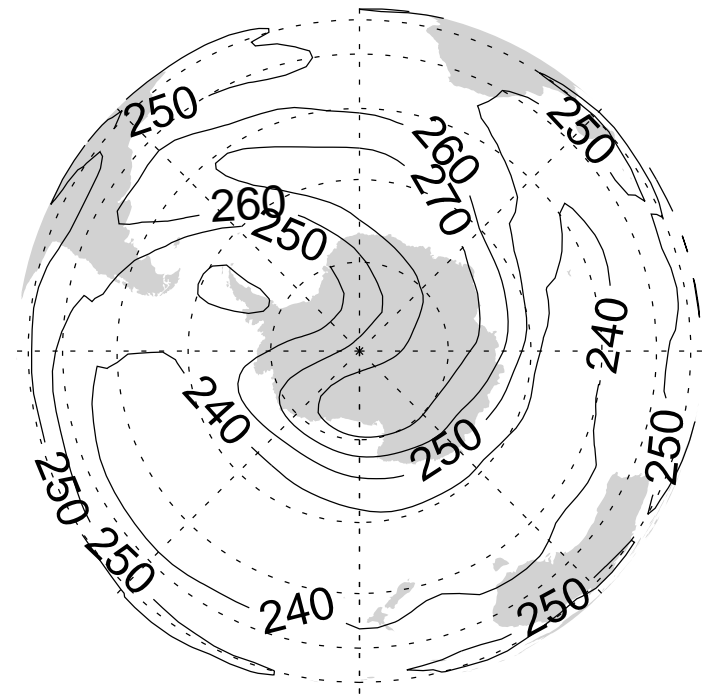

Fig. 13. Analysed temperature (in K) at $3.2 \mathrm{hPa}$ on 1 October 2003.

\subsection{Troposphere}

No ozone observations are assimilated below approximately $400 \mathrm{hPa}$, and the assimilation system must rely instead on modelled ozone photochemistry and transport here. We have already noted that the photochemistry parametrizations are not really intended for use in the troposphere. However, many current ozone assimilation systems do use Cariolletype parametrizations in the troposphere (Geer et al., 2006a). It is worth examining how large are the resulting errors.

Figure 9 shows biases of $-50 \%$ to $+100 \%$ against sonde in the troposphere. The largest biases tend to be associated with the Cariolle scheme: Cariolle v1.0 has a positive bias of over $100 \%$ in the $\mathrm{SH}$ polar troposphere, while Cariolle v2.1 has a positive bias of $80 \%$ in the tropical lower troposphere. The latter bias has also been seen in assimilation runs with the MOCAGE/PALM data assimilation system using Cariolle v2.1 photochemistry (Geer et al., 2006a). By a detailed examination of the coefficients (not shown), it appears that these positive biases arise because of ozone production by the $(P-L)_{0}$ term, which is substantially larger than those in LINOZ or Chem2D-OPP in the lower troposphere. Figure $6 a$ gives some indication of this. This model bias in the equatorial lower troposphere has been corrected from v2.3 of the Cariolle scheme onwards.

Other schemes are, because of the way they have been implemented in these experiments, dominated by the relaxation to climatology of the ozone term. For these schemes, biases are in general within $-20 \%$ to $+20 \%$, except in the NH polar lower troposphere, where biases can be as large as $-40 \%$, though results are based on very few sondes. The correct handling of tropospheric ozone remains an outstanding challenge in ozone data assimilation and a fast parametrization 
of tropospheric ozone chemistry is not yet available. Hence, a pragmatic temporary solution is to relax ozone amounts to climatology. In these experiments it is a 2-D climatology, but use of a 3-D one like Logan (1999) would capture the main zonal features of the tropospheric ozone distribution, which are visible in total column observations in the tropics. This would be important if total column observations were assimilated, so as to avoid the aliasing of tropospheric biases into changes in stratospheric ozone.

\section{Conclusion}

This study has examined ozone analyses from the Met Office stratosphere/troposphere data assimilation system. MIPAS ozone retrievals were assimilated for the period 23 September 2003 until 5 November 2003 into a set of experiments, each using a different linear ozone photochemistry parametrization. Heterogeneous chemistry was parametrized using a cold tracer scheme (Eskes et al., 2003), and remained fixed throughout the experiments. Analysed ozone was validated against independent observations from HALOE and ozonesondes. None of the ozone parametrizations is specifically intended for use in the troposphere, where modelling and observing ozone remains a substantial challenge, but results were in general good in the stratosphere and lower mesosphere.

We have also introduced a simple offline method to compare the effect of the coefficients in different parametrizations. This is done by calculating the instantaneous rate of change of ozone that would result from a representative perturbation in ozone or temperature. With this technique we were able to learn a lot about the different schemes and to show that our results can be generalised beyond the relatively short period of the assimilation experiments.

In the upper stratosphere and mesosphere, outside the polar night, the photochemical lifetime of ozone is short, and analyses are controlled mostly by the ozone parametrization, not by the assimilated observations. Here, the parametrization causes modelled ozone to relax quickly to a steady state. Hence, even though rate coefficients may vary between the different schemes, often the most important factor in controlling the modelled or assimilated ozone distribution is actually the temperature and ozone climatology supplied with each scheme. This paper illustrates the problems that can be caused when there are discrepancies between the climatologies of temperature and ozone used within the ozone parametrization and their equivalents in the GCM and in the assimilated observations. Improvements could be made by making the climatologies of ozone and temperature in the schemes more consistent with their equivalents in the GCM. In data assimilation applications, models should also be unbiased with respect to observations. In regions where the photochemical lifetime is short, this means the schemes should if possible use an ozone climatology based on the assimilated data.

In the mid and lower stratosphere, analyses strongly benefitted from the assimilation of good quality MIPAS data with a relatively high vertical resolution. Photochemical timescales are relatively slow here ( $>100$ days); any slowgrowing model biases would be corrected by the observation increments, which are added on much shorter timescales. However, a system with more sparse observational coverage for ozone (typical of operational systems) might reveal larger biases and differences between the photochemistry schemes. It is clear, however, that the data assimilation method is less able to test the photochemistry parametrizations in regions where their influence is weaker such as the lower stratosphere.

A particular example is the differing relaxation times $(\tau)$ in the Cariolle v2.1 and Chem2D-OPP v2.1 schemes in the lower stratosphere. Here, Chem2D-OPP v2.1 is roughly an order of magnitude less sensitive to ozone variations than Cariolle v2.1, mainly because Chem2D-OPP v2.1 neglects $\mathrm{Br}_{\mathrm{x}}$ chemistry, but also likely because of the different calculation methods used. However, despite the order of magnitude differences between the parametrizations, we saw no difference in analysed ozone in the lower stratosphere.

We see that data assimilation is best for testing the photochemistry schemes in regions where they have a more dominant control on the ozone amounts, such as in the mid and upper-stratosphere. Data assimilation does however force the schemes to operate in an environment as close to reality as can be provided, which model free-runs cannot do. However, it is clear that the results in this paper would be usefully complemented by long-term GCM or CTM runs which would allow slow-growing problems to be identified, and by comparisons to more detailed chemistry schemes. Chem2DOPP v2 and Cariolle v2 have been separately tested in longperiod model runs by McCormack et al. (2006) and Cariolle and Teyssèdre (2007).

We next summarise the results for each parametrization in turn. At the time the assimilation runs were made, we only had available the LINOZ, Cariolle v1.0 and v2.1, and CHEM2D-OPP v0.1 and v2.1 parametrizations. Before final publication, we have been able to examine the latest available parametrizations Cariolle v2.8 and CHEM2D-OPP v2.6, using the offline method of Sect. 2.7. A number of the discrepancies we identified in Cariolle v2.1 and CHEM2D-OPP v2.1 have now been fixed, partly in response to this study. In this work we have also examined a number of problems (such as that of LINOZ in the upper stratosphere) that are already known, but which are presented here in a wider context. In the following summary, reference is made to the earlier work in such cases. We found:

- LINOZ is unsuitable for use above $10 \mathrm{hPa}$ (McCormack et al., 2004; Geer et al., 2006a), though below this level, it generally works as well as the other schemes. 
- Cariolle v1.0 has an excessively strong dependence on overlying column ozone in the radiation term (Geer et al., 2006b), which causes excessive ozone production in the ozone hole, leading to ozone values $20 \%$ higher than sonde in the SH lower stratosphere (100 to $30 \mathrm{hPa}$ ) in the current experiments. There are also unrealistically high ozone values near the surface around Antarctica. Since these coefficients were generated many years ago (Cariolle and Déqué, 1986), it is hard to identify exactly where these problems may have come from. Elsewhere, Cariolle v1.0 works in general as well as the other schemes.

- The Cariolle v2.1 scheme performed well in general. A $\sim 20 \%$ positive bias in the tropical upper stratosphere and mesosphere was caused largely by the supplied ozone climatology, and could be partially corrected by substituting the Fortuin and Kelder (1998) climatology. Temperature and ozone terms were also too weak in the upper stratosphere and mesosphere, and this has been corrected in later versions. There was also an $80 \%$ positive bias in the tropical lower troposphere, linked to excessive ozone production in the $(P-L)_{0}$ term, which has been largely corrected in later versions of the scheme. Cariolle v2.1 analyses had particular success in the SH high latitude upper stratosphere $(6 \mathrm{hPa}$ to $1 \mathrm{hPa})$, which experienced strong minor warmings through October 2003, with synoptic temperature variations of $\sim 50 \mathrm{~K}$. Here, Cariolle v2.1 analyses showed only $6 \%$ standard deviation of difference against HALOE, compared to $10 \%$ for most other schemes and $20 \%$ for Chem2D-OPP v2.1.

- Analyses using Chem2D-OPP v0.1 (only the first two terms in Eq. 1) and v2.1 (all terms) performed well in general. Chem2D-OPP v2.1 produced unrealistic ozone structures in the $\mathrm{SH}$ polar upper stratosphere $(6 \mathrm{hPa}$ to $1 \mathrm{hPa}$ ), due primarily to an error in the ozone relaxation times, which has been fixed from v2.4 onwards. The problem was also likely exacerbated by discrepancies between analysed temperatures and the CIRA86 temperature climatology supplied with the scheme. A new temperature climatology is currently being tested, and shows promising results.

These tests are based on a short period in September to November. The precise behaviour, for example in terms of the bias in any scheme, will likely vary from region to region and through the year. Also, the exact sizes of the biases are specific to our data assimilation system and the MIPAS observations. Nevertheless, we believe that these results have wider significance. First, most of the problems we have illustrated can be explained by specific features of the coefficients in the various schemes. These features are typically persistent throughout the year and at different latitudes (Figs. 4 and 5). Hence, these figures can be used to predict where similar behaviour is likely to occur at other times of the year. Second, where the influence of the photochemistry schemes is strong, i.e. in the mid and upper-stratosphere, all models and data assimilation systems are likely to be affected in ways similar to those seen here. For example, in experiments using the KNMI system with the assimilation of only total column ozone observations (Geer et al., 2006a), the use of LINOZ caused similar biases in the upper stratosphere to those seen in Fig. 10.

Future developments of the ozone photochemistry schemes should include a better treatment of the troposphere. Also, none of these schemes simulates the diurnal cycle of ozone above $0.5 \mathrm{hPa}$, yet this has a strong influence on modelled temperatures (Sassi et al., 2005).

Acknowledgements. For the use of ozonesonde data, we thank both the individual contributors and the projects and databases from which they were obtained: WOUDC, SHADOZ and NDSC. All MIPAS data is copyright ESA, 2003. A. J. Geer, W. A. Lahoz and D. R. Jackson were funded jointly by their institutions and the Assimilation of Envisat Data project (ASSET, http://darc.nerc.ac.uk/asset/), which is a shared-cost project (contract EVK2-CT-2002-00137) co-funded by the Research DG of the European Commission within the RTD activities of the Environment and Sustainable Development sub-programme (5th Framework Programme). J. P. McCormack was funded by the Office of Naval Research and the NASA/NOAA/DoD Joint Center for Satellite Data Assimilation and was supported in part by a grant of computer time from the DoD High Performance Computing Modernization Program at the U.S. Army Engineer Research and Development Center. We thank the reviewers and editor for their help in improving the paper.

Edited by: A. Richter

\section{References}

Avallone, L. M. and Prather, M. J.: Tracer-tracer correlations: Three-dimensional model simulations and comparisons to observations, J. Geophys. Res., 102, 19233-19246, 1997.

Bhatt, P. P., Remsberg, E. E., Gordley, L. L., McInerney, J. M., Brackett, V. G., and Russell, J. M.: An evaluation of the quality of Halogen Occultation Experiment ozone profiles in the lower stratosphere, J. Geophys. Res., 104, 9261-9275, 1999.

Cariolle, D. and Déqué, M.: Southern-Hemisphere Medium-Scale Waves and Total Ozone Disturbances in a Spectral General Circulation Model, J. Geophys. Res., 91, 10 825-10 846, 1986.

Cariolle, D. and Morcrette, J.-J.: A linearized approach to the radiative budget of the stratosphere: influence of the ozone distribution, Geophys. Res. Lett., 33, L05806, doi:10.1029/2005GL025597, 2006.

Cariolle, D. and Teyssèdre, H.: A revised linear ozone photochemistry parametrization for use in transport and general circulation models: Multi-annual simulations, Atmos. Chem. Phys. Discuss., 7, 1655-1697, 2007, http://www.atmos-chem-phys-discuss.net/7/1655/2007/. 
Chipperfield, M. P.: Multiannual simulations with a threedimensional chemical transport model, J. Geophys. Res., 104, 1781-1805, 1999.

Davies, T., Cullen, M. J. P., Malcolm, A. J., Mawson, M. H., Staniforth, A., White, A. A., and Wood, N.: A new dynamical core for the Met Office's global and regional modelling of the atmosphere, Quart. J. Roy. Meteorol. Soc., 131, 1759-1782, 2005.

Dethof, A. and Hólm, E. V.: Ozone assimilation in the ERA-40 reanalysis project, Quart. J. Roy. Meteorol. Soc., 130, 2851-2872, 2004.

DeMore, W. B., Sander, S. P., Golden, D. M, Hampson, R. F., Kurylo, M. J., Howard, C. J., Ravishankara, A. R., Kolb, C. E., and Molina, M. J.: Chemical kinetics and photochemical data for use in stratospheric modelling, in: Evaluation 12, JPL Publ. 97-4, Jet Propul. Lab, Pasadena, Calif., available from http: //jpldataeval.jpl.nasa.gov/, 1997.

Errera, Q. and Fonteyn, D.: Four-dimensional chemical data assimilation of CRISTA stratospheric measurements, J. Geophys. Res., 106, 12 253-12 265, 2001.

European Space Agency: MIPAS Product Handbook, issue 1.2, available from http://envisat.esa.int/dataproducts, 2004.

Eskes, H. J., Van Velthoven, P. F. J., Valks, P. J. M., and Kelder, H. M.: Assimilation of GOME total-ozone satellite observations in a three-dimensional tracer-transport model, Quart. J. Roy. Meteorol. Soc., 129, 1663-1681, 2003.

Fischer, H. and Oelhaf, H.: Remote sensing of vertical profiles of atmospheric trace constituents with MIPAS limb-emission spectrometers, Appl. Opt., 35, 2787-2796, 1996.

Fortuin, J. P. F. and Kelder, H.: An ozone climatology based on ozonesonde and satellite measurements, J. Geophys. Res., 103, 31 709-31 734, 1998.

Geer, A. J., Lahoz, W. A., Bekki, S., Bormann, N., Errera, Q., Eskes, H. J., Fonteyn, D., Jackson, D. R., Juckes, M. N., Massart, S., Peuch, V.-H., Rharmili, S., and Segers, A.: The ASSET intercomparison of ozone analyses: method and first results, Atmos. Chem. Phys., 6, 5445-5474, 2006 a.

Geer, A. J., Peubey, C., Bannister, R. N., Brugge, R., Jackson, D. R., Lahoz, W. A., Migliorini, S., O’Neill, A., and Swinbank, R.: Assimilation of stratospheric ozone from MIPAS into a global general circulation model: the September 2002 vortex split, Quart. J. Roy. Meteorol. Soc., 132, 231-257, 2006b.

Hadjinicolaou, P., Pyle, J. A., Chipperfield, M. P., and Kettleborough, J. A.: Effect of interannual meteorological variability on mid-latitude $\mathrm{O}_{3}$, Geophys. Res. Lett., 24, 2993-2996, 1997.

Hervig, M. and McHugh, M.: Cirrus detection using HALOE measurements, Geophys. Res. Lett., 26, 719-722, 1999.

Jackson, D. R.: Improvements in data assimilation at the Met Office, Met Office Forecasting Research Technical Report, 454, available from Met Office, UK, 2004.

Jackson, D. R. and Saunders, R.: Ozone Data Assimilation: Preliminary System, Met Office Forecasting Research Technical Report, 394, available from Met Office, UK, 2002.

Josse, B., Simon, P., and Peuch, V.-H.: Radon global simulations with the multiscale chemistry and transport model MOCAGE, Tellus, 56B, 339-356, 2004.

Jet Propulsion Laboratory: Chemical Kinetics and Photochemical Data for Use in Atmospheric Studies: Evaluation Number 14, JPL publication 02-25, Jet Propulsion Laboratory, California Institute of Technology, Pasadena, California, USA, available from http://jpldataeval.jpl.nasa.gov/, 334 pp., 2003.

Komhyr, W. D., Barnes, R. A., Brothers, G. B., Lathrop, J. A., and Opperman, D. P.: Electrochemical Concentration Cell Ozonesonde Performance Evaluation During STOIC 1989, J. Geophys. Res., 100, 9231-9244, 1995.

Lahoz, W. A., Geer, A. J., and O'Neill, A.: Dynamical evolution of the 2003 Southern Hemisphere stratospheric winter using Envisat trace-gas observations, Quart. J. Roy. Meteorol. Soc., 132, 1985-2008, 2006.

Logan, J. A.: An analysis of ozonesonde data for the troposphere: Recommendations for testing 3-D models and development of a gridded climatology for tropospheric ozone, J. Geophys. Res., 104, 16 115-16 149, 1999.

Lorenc, A. C., Ballard, S. P., Bell, R. S., Ingleby, N. B., Andrews, P. L. F., Barker, D. M., Bray, J. R., Clayton, A. M., Dalby, T. D., Li, D., Payne, T. J., and Saunders, F. W.: The Met. Office global three-dimensional variational data assimilation scheme, Quart. J. Roy. Meteorol. Soc., 126, 2991-3012, 2000.

McCormack, J. P., Eckermann, S. D., Coy, L., Allen, D. R., Kim, Y.J., Hogan, T., Lawrence, B., Stephens, A., Browell, E. V., Burris, J., McGee, T., and Trepte, C. R.: NOGAPS-ALPHA model simulations of stratospheric ozone during the SOLVE2 campaign, Atmos. Chem. Phys., 4, 2401-2423, 2004, http://www.atmos-chem-phys.net/4/2401/2004/.

McCormack, J. P., Eckermann, S. D., Siskind D. E., and Coy, L.: A new linearized gas-phase ozone photochemistry parameterization for high-altitude NWP and climate models, Atmos. Chem. Phys., 6, 4943-4972, 2006,

http://www.atmos-chem-phys.net/6/4943/2006/.

McLinden, C. A., Olsen, S. C., Hannegan, B., Wild, O., Prather, M. J., and Sundet, J.: Stratospheric ozone in 3-D models: A simple chemistry and the cross-tropopause flux, J. Geophys. Res., 105, 14 653-14 665, 2000.

McPeters, R.: Ozone profile comparisons, in: The Atmospheric Effects of Stratospheric Aircraft: Report of the 1992 Models and Measurements Workshop, NASA Ref. Publ. 1292, edited by: Prather, M. J. and Remsberg, E. E., D1-D37, 1993.

Nagatani, R. M. and Rosenfield, J. E.: Temperature, net heating and circulation, in: The Atmospheric Effects of Stratospheric Aircraft: Report of the 1992 Models and Measurements Workshop, NASA Ref. Publ. 1292 edited by: Prather, M. J. and Remsberg, E. E., A1-A47, 1993.

Natarajan, M., Remsberg, E. E., and Gordley, L. L.: Ozone budget in the upper stratosphere: Model studies using the reprocessed LIMS and the HALOE datasets, Geophys. Res. Lett., 29, 1152, doi:10.1029/2001GL014262, 2002.

Plumb, R. A.: Stratospheric transport, J. Meteorol. Soc. Jpn., 80, 793-809, 2002.

Prather, M. J.: Catastrophic loss of stratospheric ozone in dense volcanic clouds, J. Geophys. Res., 97, 10 187-10 191, 1992.

Prather, M. J. and Jaffe, A. H.: Global impact of the antarctic ozone hole: Chemical propagation, J. Geophys. Res., 95, 3473-3492, 1990.

Randel, W., Udelhofen, P., Fleming, E., Geller, M., Gelman, M., Hamilton, K., Karoly, D., Ortland, D., Pawson, S., Swinbank, R., Wu, F., Baldwin, M., Chanin, M. L., Keckhut, P., Labitzke, K., Remsberg, E., Simmons, A., and Wu, D.: The SPARC intercomparison of middle-atmosphere climatologies, J. Climate, 17, 986-1003, 2004. 
Riishøjgaard, L. P., S̆tajner, I., and Lou, G.-P.: The GEOS ozone data assimilation system, Adv. Space Res., 25, 1063-1072, 2000.

Rozanov, E. V., Zubov, V. A., Schlesinger, M. E., Yang, F., and Andronova, N. G.: The UIUC three-dimensional stratospheric chemical transport model: Description and evaluation of the simulated source gases and ozone, J. Geophys. Res., 104, 11755$11781,1999$.

Russell, J. M., Gordley, L. L., Park, J. H., Drayson, S. R., Hesketh, W. D., Cicerone, R. J., Tuck, A. F., Frederick, J. E., Harries, J. E., and Crutzen, P. J.: The Halogen Occultation Experiment, J. Geophys. Res., 98, 10777-10 797, 1993.

Sassi, F., Boville, B. A., Kinnison, D., and Garcia, R. R.: The effects of interactive ozone chemistry on simulations of the middle atmosphere, Geophys. Res. Lett., 32, L07811, doi:10.1029/2004GL022131, 2005.

Schoeberl, M. R., Douglass, A. R., Zhu, Z. X., and Pawson, S.: A comparison of the lower stratospheric age spectra derived from a general circulation model and two data assimilation systems, J. Geophys. Res., 108, 4113, doi:10.1029/2002JD002652, 2003.

Siegmund, P., Eskes, H. J., and Van Velthoven, P. F. J.: Antarctic ozone transport and depletion in austral spring 2002, J. Atmos. Sci., 62, 838-847, 2005.

Siskind, D. E., Eckermann, S. D. , McCormack, J. P., Alexander, M. J., and Bacmeister, J. T.: Hemispheric differences in the temperature of the summertime stratosphere and mesosphere, J. Geophys. Res., 108, 4051, doi:10.1029/2002JD002095, 2003.
Taylor, C. P. and Bourqui, M. S.: A new fast stratospheric ozone chemistry scheme in an intermediate general-circulation model. I: Description and evaluation, Quart. J. Roy. Meteorol. Soc., 131, 2225-2242, 2005.

Thompson, A. M., Witte, J. C., McPeters, R. D., Oltmans, S. J., Schmidlin, F. J., Logan, J. A., Fujiwara, M., Kirchhoff, V. W. J. H., Posny, F., Coetzee, G. J. R., Hoegger, B., Kawakami, S., Ogawa, T., Johnson, B. J., Vomel, H., and Labow, G.: Southern Hemisphere Additional Ozonesondes (SHADOZ) 1998-2000 tropical ozone climatology - 1. Comparison with Total Ozone Mapping Spectrometer (TOMS) and ground-based measurements, J. Geophys. Res., 108, 8238, doi:10.1029/2001JD000967, 2003a.

Thompson, A. M., Witte, J. C., Oltmans, S. J., Schmidlin, F. J., Logan, J. A., Fujiwara, M., Kirchhoff, V. W. J. H., Posny, F., Coetzee, G. J. R., Hoegger, B., Kawakami, S. J., Ogawa, T., Fortuin, J. P. F., and Kelder, H. M.: Southern Hemisphere Additional Ozonesondes (SHADOZ) 1998-2000 tropical ozone climatology -2 . Tropospheric variability and the zonal wave-one, J. Geophys. Res., 108, 8241, doi:10.1029/2002JD002241, 2003b.

World Meteorological Organisation: Scientific assessment of ozone depletion: 2002, Global Ozone Research and Monitoring Project-Report No. 47, 498 pp., Geneva, 2003. 